\title{
Characterizing the Formation of Secondary Organic Aerosols
}

\author{
Interim Report \\ Melissa Lunden, Douglas Black, and Nancy Brown \\ Environmental Energy Technologies Division \\ Lawrence Berkeley National Laboratory \\ Berkeley, CA 94720-1740 \\ Prepared for the \\ National Petroleum Technology Office \\ And the \\ Independent Association of Mountain States
}

FEBRUARY, 2004

\author{
Contact person \\ Dr. Nancy J. Brown \\ Phone: (510) 486-4241 \\ Fax: (510) 486-7303 \\ e-mail: njbrown@lbl.gov
}

This research was supported by the Assistant Secretary for Fossil Energy, Office of Natural Gas and Petroleum Technology, through the National Petroleum Technology Office under U.S. Department of Energy Contract No. DE-AC03765F00098 and the Independent Petroleum Association of Mountain States. 


\section{Executive Summary}

Organic aerosol is an important fraction of the fine particulate matter present in the atmosphere. This organic aerosol comes from a variety of sources; primary organic aerosol emitted directly from combustion process, and secondary aerosol formed in the atmosphere from condensable vapors. This secondary organic aerosol (SOA) can result from both anthropogenic and biogenic sources. In rural areas of the United States, organic aerosols can be a significant part of the aerosol load in the atmosphere. However, the extent to which gas-phase biogenic emissions contribute to this organic load is poorly understood. Such an understanding is crucial to properly apportion the effect of anthropogenic emissions in these rural areas that are sometimes dominated by biogenic sources.

To help gain insight on the effect of biogenic emissions on particle concentrations in rural areas, we have been conducting a field measurement program at the University of California Blodgett Forest Research Facility. The field location includes has been used to acquire an extensive suite of measurements resulting in a rich data set, containing a combination of aerosol, organic, and nitrogenous species concentration and meteorological data with a long time record. The field location was established in 1997 by Allen Goldstein, a professor in the Department of Environmental Science, Policy and Management at the University of California at Berkeley to study interactions between the biosphere and the atmosphere. The Goldstein group focuses on measurements of concentrations and whole ecosystem biosphere-atmosphere fluxes for volatile organic compounds (VOC's), oxygenated volatile organic compounds (OVOC's), ozone, carbon dioxide, water vapor, and energy. Another important collaborator at the Blodgett field location is Ronald Cohen, a professor in the Chemistry Department at the University of California at Berkeley. At the Blodgett field location, his group his group performs measurements of the concentrations of important gas phase nitrogen compounds.

Experiments have been ongoing at the Blodgett field site since the fall of 2000, and have included portions of the summer and fall of 2001, 2002, and 2003. Analysis of both the gas and particle phase data from the year 2000 show that the particle loading at the site correlates with both biogenic precursors emitted in the forest and anthropogenic precursors advected to the site from Sacramento and the Central Valley of California. Thus the particles at the site are affected by biogenic processing of anthropogenic emissions.

Size distribution measurements show that the aerosol at the site has a geometric median diameter of approximately $100 \mathrm{~nm}$. On many days, in the early afternoon, growth of nuclei mode particles $(<20 \mathrm{~nm})$ is also observed. These growth events tend to occur on days with lower average temperatures, but are observed throughout the summer. Analysis of the size resolved data for these growth events, combined with typical measured terpene emissions, show that the particle mass measured in these nuclei mode particles could come from oxidation products of biogenic emissions, and can serve as a significant route for SOA partitioning into the particle phase. 
During periods of each year, the effect of emissions for forest fires can be detected at the Blodgett field location. During the summer of 2002 emissions from the Biscuit fire, a large fire located in Southwest Oregon, was detected in the aerosol data. The results show that increases in particle scattering can be directly related to increased black carbon concentration and an appearance of a larger mode in the aerosol size distribution. These results show that emissions from fires can have significant impact on visibility over large distances. The results also reinforce the view that forest fires can be a significant source of black carbon in the atmosphere, which has important climate and visibility.

Continuing work with the 2002 data set, particularly the combination of the aerosol and gas phase data, will continue to provide important information on the extent to which biogenic emissions contribute to secondary organic aerosol and may elucidate important interactions between anthropogenic and biogenic sources. The results of these studies, performed in the field, will contribute to the growing effort to produce robust models for particulate formation that are necessary for air quality planning and source apportionment. 


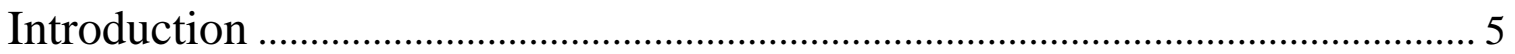

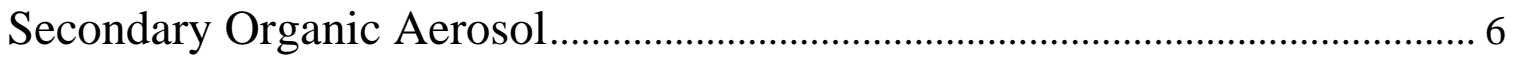

Theory of Secondary Organic Aerosol Formation......................................................... 6

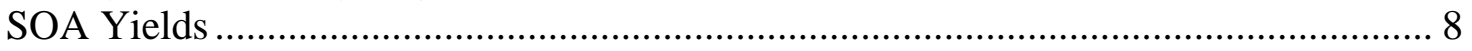

Experimental Investigations of SOA Formation....................................................... 9

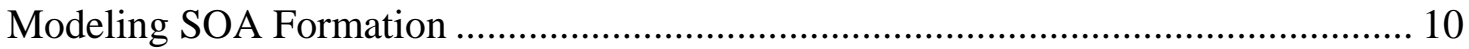

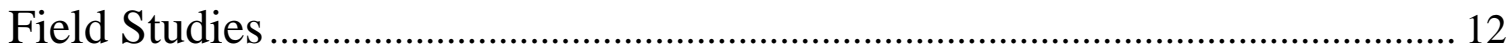

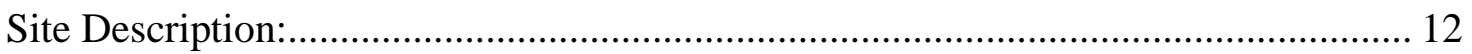

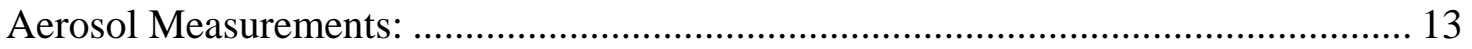

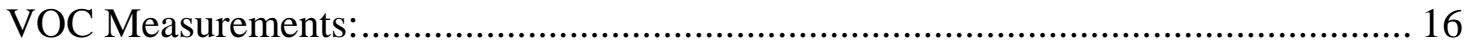

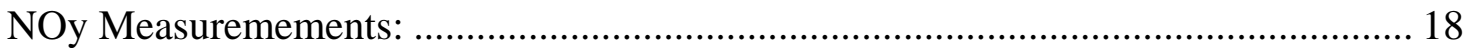

Meteorlogical and other measurements: .................................................................... 19

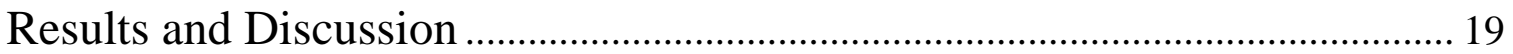

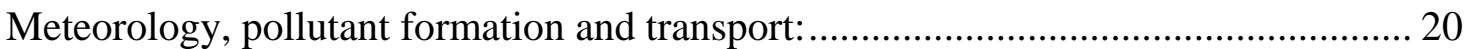

Particle formation and growth: .................................................................................. 22

Aerosol impacts due to forest fire emissions: ........................................................... 29

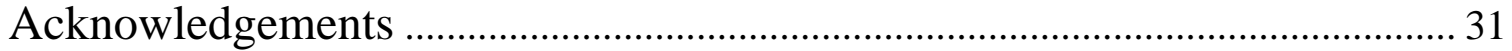

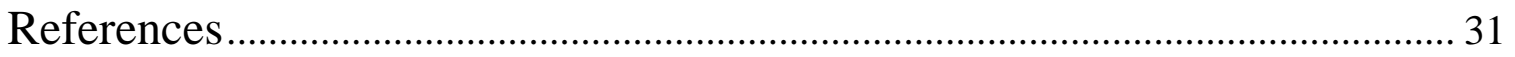




\section{Introduction}

Fine particulate matter comes from a number of sources, and has received considerable attention lately due to aerosol influences on human health, global climate, and visibility. An important fraction of particulate matter is organic aerosol. For example, organic compounds contribute from 10 to $70 \%$ of dry fine particle mass in the atmosphere. (U.S. EPA, Air Quality Criteria for Particulate Matter (Fourth External Review Draft), 2003.) This organic aerosol consists of primary aerosol, emitted directly from the sources as an aerosol, and secondary, formed in-situ in the atmosphere from condensable vapors. Primary organic aerosols often result from combustion processes. (Rogge et al., 1993, Schauer et al. 1999a,b, 2001) Secondary organic aerosol (SOA) is formed from the atmospheric oxidation of volatile organic compounds to produce condensable species. Secondary organic aerosols form when organic vapors emitted into the atmosphere are oxidized to produce less volatile products. These products then partition between the gas and particle phase. SOA production from a given VOC depends on: (1) the abundance and reactivity of the given VOC compound; (2) the abundance of radicals in the atmosphere; (3) the nature of its reaction pathways; (4) the volatility and gas-to-particle partitioning properties of its products; (5) the ambient aerosol mass concentration; and (6) temperature.

SOA can form from both anthropogenic and biogenic precursors. The contribution of biogenic precursors to SOA can be significant. Terrestrial vegetation releases a number of reactive organic compounds into the atmosphere, including isoprene, monoterpenes, sesquiterpenes, and others. The total annual global biogenic organic emissions are estimated to be $1150 \mathrm{Tg} \mathrm{yr}^{-1}$, while the estimate for total anthropogenic emissions is 142 $\mathrm{Tg}^{-1} \mathrm{yr}^{-1}$ (Seinfeld and Pandis, 1998)

Our knowledge of the chemistry of SOA formation is not well understood, particularly in rural environments where the role of biogenic SOA formation is of greater importance. Much of the research on biogenic emissions has been performed in the Eastern and Southern United States. There is limited information on the emissions from the pine forest that dominate much of the Western United States. Research concerning SOA formation from biogenic organic emissions is sparse, and primarily consists of controlled experiments in laboratory smog chambers. There are very few field measurements of speciated biogenic gas phase measurements coupled with aerosol characterization measurements. These would serve as a comparison to SOA products and yields measured in laboratory experiments. An understanding of the reaction pathways, kinetics, and aerosol forming behavior of biogenic emission sources is important to understanding regional air quality issues including particle loading, ozone formation, and visibility.

The objective of this study is to investigate the biosphere-atmosphere exchange of VOCs and their effects on aerosol formation and processing. This is being achieved by conducting aerosol characterization measurements in concert with measurements of the gas phase concentrations of biogenic and anthropogenic VOCs and meteorological variables over the period of several months at an established sampling site located at the 
University of California Blodgett Forest Research Station. The field site is located on the western slope of the Sierra Nevada Mountains, approximately $75 \mathrm{~km}$ northeast of Sacramento at the site of an evenly aged ponderosa pine plantation. This project provides crucial data needed to characterize the formation of biogenic SOA under actual conditions in the rural atmosphere. The field program offers the advantage of having all atmospheric reactants present at atmospheric concentrations, something that is not usually achieved with smog chamber experiments. Data are collected over an extended period of time, providing data during both the height of summer and cooler periods in the spring and fall. The results from the study contribute to the understanding of the chemistry active in the formation of SOA, and provide critical information necessary for the modeling of SOA.

This report provides a brief review of the theory behind SOA formation, relevant experimental results, and approaches to modeling SOA behavior. The report will also provide details on the experimental design of the Blodgett forest research site. Finally, the report will present initial results from the field site.

\section{Secondary Organic Aerosol}

The interactions between organic gases and aerosols in the atmosphere are complex. Some organic aerosol can be directly emitted into the atmosphere as a result of fossil fuel combustion or biomass burning; these organic aerosols are termed primary organic aerosol (POA). A large fraction of organic gases are volatile, and are therefore emitted into the atmosphere in the gas phase. These organic gases are generally quite reactive and are thus termed reactive organic gases (ROG). The oxidation of ROGs is a key step in the formation of photochemical smog. In addition, the oxidation products of some ROGs have sufficiently low vapor pressure that they partition into the aerosol phase. The aerosol that is comprised of these condensed products of ROG oxidation is called secondary organic aerosol. SOA is important because it can form a significant fraction of the fine particle burden in both rural and urban regions. In addition, there is evidence to suggest that the organic fraction is suspected to contribute to the adverse health effects of particulate matter. (Dreher 2000, Mauderly 2003)

\section{Theory of Secondary Organic Aerosol Formation}

The atmospheric chemical reaction pathways of ROGs are complex, leading to a large number of oxidation products, all of which have different propensities to condense and form SOAs. These chemical pathways can be depicted in general terms as follows. Consider the production of semivolatile organic gases, S1, S2, ... from the gas-phase reaction of the parent hydrocarbon, HC, with the OH radical. (Griffen 1999, Pankow 1994a,b)

$$
\mathrm{HC}+\mathrm{OH} \stackrel{k_{\mathrm{OH}}}{\longrightarrow} \ldots+\alpha_{1} S_{1}+\alpha_{2} S_{2}+\ldots
$$

where $\mathrm{k}_{\mathrm{OH}}$ is the $\mathrm{OH}$ reaction rate constant, and $\alpha_{1}, \alpha_{2}, \ldots$ are the product stoichiometric coefficients. It is also possible for many hydrocarbons to react with $\mathrm{O}_{3}$ and $\mathrm{NO}_{3}$ radicals, providing additional pathways for semivolatile product formation, 


$$
\begin{gathered}
\mathrm{HC}+\mathrm{O}_{3} \stackrel{k_{\mathrm{O}_{3}}}{\longrightarrow} \ldots+\alpha_{1, \mathrm{O}_{3}} S_{1, \mathrm{O}_{3}}+\alpha_{2, \mathrm{O}_{3}} S_{2, \mathrm{O}_{3}}+\ldots \\
\mathrm{HC}+\mathrm{NO}_{3} \stackrel{k_{\mathrm{NO}_{3}}}{\longrightarrow} \ldots+\alpha_{1, \mathrm{NO}_{3}} S_{1, \mathrm{NO}_{3}}+\alpha_{2, \mathrm{NO}_{3}} S_{2, \mathrm{NO}_{3}}+\ldots
\end{gathered}
$$

The first generation products $\mathrm{S} 1, \mathrm{~S} 2$... may subsequently undergo gas-phase reactions themselves, creating another generation of condensable products, $S_{1 \mathrm{a}}, \mathrm{S}_{1 \mathrm{~b}}, \ldots$ and $\mathrm{S}_{2 \mathrm{a}}, \mathrm{S}_{2 \mathrm{~b}}$, ... etc.

$$
\begin{aligned}
& S_{1}+\mathrm{OH} \underset{\mathrm{kH}_{\mathrm{OS}} \mathrm{L}}{\longrightarrow} \ldots+\alpha_{1 a} S_{1 a}+\alpha_{1 b} S_{1 b}+\ldots \\
& S_{2}+\mathrm{OH} \stackrel{k_{\mathrm{OH}, S_{2}}}{\longrightarrow} \ldots+\alpha_{2 a} S_{2 a}+\alpha_{2 b} S_{2 b}+\ldots
\end{aligned}
$$

Initially, it was believed that each parent ROG possessed a unique value for the amount of SOA formed from the reaction of each ROG. (Grosjean 1989, Pandis et al., 1992, 1993) These theories contrasted with measured yields for individual organic gases that showed a degree of variation that cannot be reconciled by such a single value theory. An improvement over this approach was presented in Pandis et al. (1992), where each secondary organic reaction product was assigned a volatility based upon its saturation vapor pressure. Under conditions where the gas phase concentration exceeds its saturation vapor pressure, the excess was assumed to condense into the aerosol phase. If the atmospheric concentration was reduced below this saturation concentration, a portion of the condensed product was assumed to return to the gas phase, thus the model allowed for the secondary reaction products to partition reversibly between the aerosol and gas phases depending upon atmospheric conditions and concentrations.

The authors recognized that this modeling approach likely underestimated the total amount of gas-to-particle conversion that occurs, due to the fact that both adsorption of the secondary product onto available particle surfaces and/or absorption of the gas phase compound into pre-existing organic aerosol phase allows for gas-to-particle conversion below the saturation vapor pressure.

Pankow (1994a) developed a combination adsorption/absorption model in order to describe SOA formation at gas phase concentrations below the saturation vapor pressure. As a starting point, the equation used to parameterize gas/particle partitioning is

$$
K_{p}=\frac{A_{i} / T S P}{G_{i}}
$$

where $\mathrm{K}_{\mathrm{p}}\left(\mathrm{m}^{3} \mu \mathrm{g}^{-1}\right)$ is a temperature-dependent partitioning constant, TSP ( $\left.\mu \mathrm{g} \mathrm{m}^{-3}\right)$ is the concentration of total suspended particulate matter, $A_{i}\left(\mu \mathrm{g} \mathrm{m}^{-3}\right)$ is the fraction of the organic compound $i$ in the particle phase and $G_{i}\left(\mu \mathrm{g} \mathrm{m}^{-3}\right)$ is the fraction in the gas phase. This equation does not assume anything about the nature of the partitioning.

If partitioning is simple physical adsorption, then the partitioning coefficient can be calculated as

$$
K_{p}=\frac{N_{s} a_{t s p} T e^{\left(Q_{1}-Q_{v}\right) / R T}}{1600 p_{L}^{\circ}}
$$

where $\mathrm{N}_{\mathrm{s}}$ ( sites $\mathrm{cm}^{-2}$ ) is the surface concentration of sorption sites, $\mathrm{a}_{\text {tsp }}\left(\mathrm{m}^{2} \mathrm{~g}^{-1}\right)$ is the specific surface area of the aerosol, $\mathrm{Q}_{1}\left(\mathrm{~kJ} \mathrm{~mol}^{-1}\right)$ is the enthalpy of desorption from the 
surface, $\mathrm{Q}_{\mathrm{v}}\left(\mathrm{kJ} \mathrm{mol}^{-1}\right)$ is the enthalpy of vaporization of the liquid (sub-cooled if necessary), $\mathrm{p}_{\mathrm{L}}{ }^{0}$ is the vapor pressure (torr) of the compound of interest (sub-cooled if necessary), $\mathrm{R}$ is the gas constant, and $\mathrm{T}$ is the temperature $(\mathrm{K})$.

The partitioning coefficient for absorption can be defined as

$$
K_{p, i}=\frac{760 R T f_{o m}}{M W_{o m} 10^{6} \zeta_{i} p_{L, i}^{\circ}}
$$

where $f_{\text {om }}$ is the mass fraction of the aerosol that is the absorbing organic matter, $M_{\text {om }}$ $\left(\mathrm{g} \mathrm{mol}^{-1}\right)$ is the mean molecular weight of the absorbing organic matter, $\zeta_{\mathrm{i}}$ is the activity coefficient of compound $i$ in the organic matter phase, and $\mathrm{p}_{\mathrm{L}, \mathrm{i}}{ }^{0}$ is the vapor pressure of the absorbing compound as a liquid (sub-cooled if necessary.) The factor of $10^{6}$ accomplishes the appropriate unit conversions. A similar partitioning coefficient can be defined for the total amount of condensed organic material rather than the total aerosol mass as,

$$
K_{o m, i}=\frac{A_{i} / M_{o}}{G_{i}}=\frac{K_{p, i}}{f_{o m}}
$$

where $\mathrm{M}_{\mathrm{o}}$ is total amount of organic in the aerosol. $\mathrm{K}_{\mathrm{om}, \mathrm{i}}$ is constant at a particular temperature, therefore Eq. 8 implies that as the total organic aerosol fraction increases, the fraction of species i that will partition into the aerosol phase will also increase.

\section{SOA Yields}

The most accepted approach to describe the amount of SOA formed from a specific parent reactive organic gas is the fraction mass yield, Y. (Pandis et al. 1991, Odum et al. 1996, Hoffman et al. 1997, Griffin et al. 1999) The yield for each product $i$ is the mass concentration of SOA produced from the oxidation of ROG and it is defined as

$$
Y_{i}=\frac{A_{i}}{\triangle R O G}
$$

where $\triangle \mathrm{ROG}$ is the amount of the ROG that has reacted. The total SOA yield for product i will be the sum of the individual product yields

$$
Y=\sum_{i=1}^{N} Y_{i}
$$

where $\mathrm{N}$ is the total number of condensable products.

The total concentration of each oxidation product $\mathrm{i}, \mathrm{C}_{\mathrm{i}}$, is proportional to the amount of parent hydrocarbon that reacts

$$
\alpha_{i} \Delta R O G=C_{i} .
$$

(It is important to note that in Eq. 11, $\alpha_{i}$ is a mass-based stoichiometric coefficient, which can be related to the more traditional molar stoichiometric coefficient by the ratio of the molecular weights of the product to the precursor hydrocarbon, $\left.\alpha_{i, m a s s}=\alpha_{i, m o l} M W_{i} / M W_{R O G}.\right) C_{i}$ is also equal to the sum of gas $\left(\mathrm{G}_{\mathrm{i}}\right)$ and $\operatorname{aerosol}\left(\mathrm{A}_{\mathrm{i}}\right)$ phase concentrations of $\mathrm{i}$,

$$
C_{i}=G_{i}+A_{i} \text {. }
$$


Combining Eqs. 8 through 12 provides an expression for the fractional mass yield as a function of the organic partitioning coefficient, $\mathrm{K}_{\mathrm{om}, \mathrm{i}}$ and the organic aerosol mass concentration, $\mathrm{M}_{0}$,

$$
Y=M_{0} \sum_{i=1}^{N} \frac{\alpha_{i} K_{\text {om }, i}}{1+K_{o m, i} M_{0}} .
$$

It is interesting to examine the limits of the yield formula. When the concentration of organic mass is small, or the volatility of the products is high (decreasing the value of $\mathrm{K}_{\mathrm{om}, \mathrm{i}}$ ), the yield is directly proportional to $\mathrm{M}_{0}$,

$$
Y \sim M_{o} \sum_{i=1}^{N} \alpha_{i} K_{o m, i}
$$

In the limit of large $\mathrm{M}_{0}$ or products of low volatility the yield is independent of $\mathrm{M}_{0}$,

$$
Y \sim \sum_{i=1}^{N} \alpha_{i}
$$

and is simply the sum of the mass-based stoichiometric coefficients of the products.

The theory detailed above has been successfully employed to describe SOA yield data from smog chamber experiments. (Odum et al, 1996,1997, Griffen et al, 1999) These experiments resulted in a series of yield data for different amounts of reacted parent hydrocarbon, and were fitted using Eq. 13. The results of these experiments, conducted for a variety of parent hydrocarbons, were adequately described by two hypothetical products resulting in four fitted parameters, $\alpha_{1}, \mathrm{~K}_{\mathrm{om}, 1}, \alpha_{2}$, and $\mathrm{K}_{\mathrm{om}, 2}$. These two products can be roughly thought of as the SOA yields for an average low and high vapor pressure product, respectively.

While the finding that the two-product model successfully fits laboratory data was an important result, the model is semi-empirical, and as such is not a suitable method for predictively modeling the more complex systems found in the atmosphere. Such a predictive approach is difficult to implement due to an incomplete knowledge of the important reaction products and stoichiometric coefficients for each ROG, and the unavailability of thermodynamic data necessary to provide a values of the vapor pressure $\mathrm{p}_{\mathrm{L}}{ }^{0}$ and the activity coefficients $\zeta_{\mathrm{i}}$ for each reaction product. Note that $\zeta_{\mathrm{i}}$ is a function of the SOA mixture composition.

\section{Experimental Investigations of SOA Formation}

Experimental studies of secondary organic aerosol formations have largely employed laboratory chambers. These chamber studies provide a means to investigate mechanistic understanding of individual chemical and physical processes that would be difficult to study in the atmosphere due to the complexities inherent in atmospheric flow and mixing process. Chamber studies allow for detailed, lab-based characterization of gas-phase species and species concentrations, aerosol size distribution, and aerosol chemical characterization. The chambers usually are at least a few cubic meters in volume in order to minimize the losses to the chamber walls, and are primarily constructed of Teflon as a non-reactive surface. Both natural and artificial sunlight are used to drive the chemical processes in the chambers. Outdoor chambers use the available natural light to perform 
experiments, however experiment reproduction can be difficult due to weather and atmospheric variability. Indoor chambers use artificial lights to simulate sunlight, and allow for more precise control of light, temperature, and relative humidity, allowing for better reproducibility between experiments. There is some concern that the artificial light does not simulate the solar spectrum as closely as desired.

Chamber experiments have been performed for a number of different compounds in the last decade, including aromatic hydrocarbons that are prevalent in gasoline (Odum et al. 1996, 1997, Jang and Kamens 2001, Kleindienst et al. 1999) and biogenic hydrocarbons (Hoffman et al.1997, Jang and Kamens 1999, Griffen et al. 1999, Yu et al. 1999a, Cocker et al. 2001, Kamens and Jaoui 2001). The laboratory studies have utilized as an oxidant $\mathrm{O}_{3}$ reactions, $\mathrm{NO}_{\mathrm{x}}$ photooxidation, and $\mathrm{OH}$ reactions. The results have shown that formation of SOA from terpenes is significant, exceeding the formation rates measured for typical aromatic compounds found in gasoline. Of all the VOC's studies, sesquiterpenes show the highest SOA formation potential.

Several recent studies have provided direct measurements of the condensation of the oxidation products of biogenic hydrocarbons in forest atmospheres. (Kavouras et al. 1998, Leaitch et al. 1999, Yu et al. 1999, O’Dowd et al. 2002) Yu et al. (1999b,c) used laboratory filter-based organic compound speciation techniques to identify monoterpene oxidation components of organic aerosol from forests in both California and Nova Scotia.

\section{Modeling SOA Formation}

SOA formation is a highly complex process that depends on a thorough understanding of the emissions of the parent hydrocarbons, their gas phase oxidation pathways and reaction rates, the stoichiometry of the oxidation products, and the thermodynamics of these products in the condensed phase. This section briefly focuses on the modeling efforts of the research community to date, and the strengths and limitations of each approach.

The most basic of the approaches to SOA modeling has been to use measured experimental yield parameters in oxidation models for the smog chamber. (Hoffman et al. 1997, Bowman et al. 1997, Bathelemie and Pryor 1999) This approach employs a box model of the chamber, with known initial conditions. When coupled with appropriate time resolved gas phase data, this approach enables detailed analysis of smog chamber results with a goal of understanding the evolution of the system over time. The results can provide information about the importance of different oxidation pathways and detail of the microphysical processes that provide routes to aerosol formation. This modeling approach is limited when applied to the atmosphere because the atmosphere is not a constant and/or controlled environment. Its behavior is not deterministic but stochastic, and can be quite variable.

Recently, there have been attempts to model SOA yields of specific organic precursors, such as alpha-pinene, using a relatively complete detailed description of the photochemical oxidation products. (Pankow et al., 2001, Seinfeld et al., 2001) These 
models have been used to calculate yield parameters from know oxidation products and theoretically derived thermodynamics. A few laboratory investigations exist that were able to identify and quantify appreciable fractions of the organic compounds contributing to SOA for a few parent hydrocarbons. (Yu et al. 1999, Kalberer et al. 2000) The values of the stoichiometric coefficients, $\alpha_{\mathrm{i}}$, were determined experimentally. Values for $\mathrm{p}_{\mathrm{L}}{ }^{0}$ and $\zeta_{\mathrm{i}}$ were estimated using UNIFAC (Universal Quasi-Chemical Functional Group Activity Coefficients) principles. ${ }^{1}$ The model was able to successfully predict aerosol yield values for five different hydrocarbons using ozone as an oxidant, thus providing good evidence that SOA formation can be modeled by using a multicomponent absorbtive partitioning process. This type of modeling also offers possible insight on the usefulness of a proposed chemical mechanism for the oxidation of a specific parent hydrocarbon, or a corroboration of experimentally determined yield data.

Some recent efforts have addressed the representation of the formation of secondary organic aerosol in atmospheric models. (Griffin et al. 2002a,b, 2003, Pun et al. 2002) These models used the Statewide Air Pollution Research Center (SAPRC) mechanism, modified to represent both ozone chemistry as well as the formation of individual organic oxidation products that are capable of forming SOA. In the mechanism, individual parent organics were aggregated into lumped surrogate structures. A thermodynamic equilibrium partitioning model was developed that considered both hydrophobic and hydrophilic constituents. As in the previously discussed models, individual compound activities and the liquid vapor pressure were calculated using UNIFAC. The gas phase mechanism and thermodynamics were combined into a 3-D chemical transport model and used to simulate gas and aerosol concentrations during a 1993 smog episode in Southern California. The results of the models show that the SOA formation in urban areas is dominated by the partitioning of hydrophobic organic compounds formed from the oxidation of anthropogenic organics. In addition, they found that the biogenic contribution to total SOA increased in rural areas as did the fraction of hydrophilic SOA. This type of modeling is clearly the most detailed, and will be necessary for modeling areas for compliance purposes. However, this model requires detailed information on meteorology and emissions, as well as a data set to be compared to, which are not available in many areas. Biogenic emissions inventories are particularly problematic emissions from many important species in the Sierra Nevadas are not well characterized.

\footnotetext{
${ }^{1}$ The UNIFAC method uses the idea of a solution-of-groups model utilizing existing phase equilibrium data to predict phase equilibria for systems where no experimental data exist. The method represents the molecules in a mixture by a system of structural subgroups. The properties of the subgroups and interactions between the subgroups are used to calculate activity coefficients.
} 


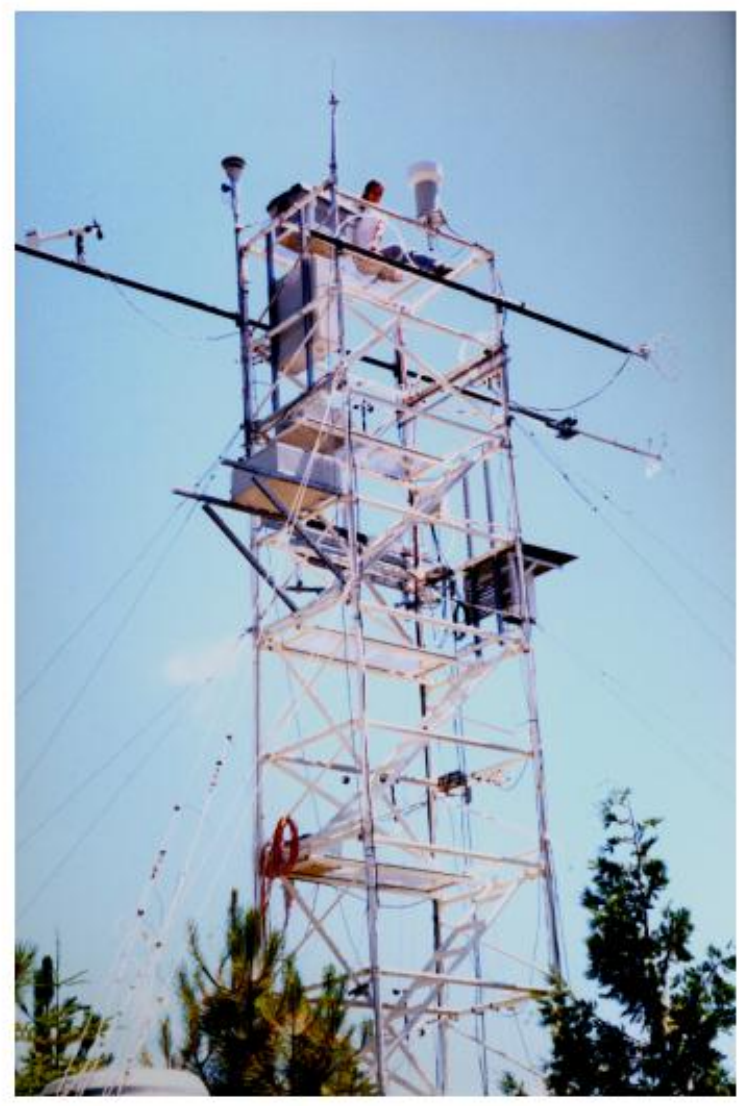

Figure 1: Picture of the tower at the Blodgett Forest Field Site. The boxes mounted on the tower contain the aerosol equipment.

\section{Field Studies}

\section{Site Description:}

The field site is near the Blodgett Forest Research Station (3853'42.9'N, $120^{\circ} 37^{\prime} 57.9$ 'W, $1315 \mathrm{~m}$ ) on the western slope of the Sierra Nevada Mountains in California, approximately $75 \mathrm{~km}$ northeast of Sacramento. Measurements at the site were established in 1997 in order to investigate the transport processes and photochemistry that occurs as air moves upslope carrying air pollution to our site in a regular diurnal pattern. (Dillon et al. 2002, Dreyfus et al. 2002) The site is characterized by a Mediterranean climate, with warm dry summers and rainfall between September and May. The site is an evenly aged ponderosa pine plantation owned by Sierra Pacific Industries planted in 1990. Measurements were conducted using a 12-m walk-up tower, shown in Figure 1.

The meteorology at the site is fairly consistent. The predominant daytime airmass trajectory is upslope from the Sacramento Valley in the southwest direction, carrying anthropogenic pollutants from Sacramento and the agricultural Central Valley of California. During the evening, a drainage flow moves cleaner air downslope from the Sierra Nevada Mountains in the North East direction. 
The site is powered by a diesel generator located $\sim 130 \mathrm{~m}$ to the northwest of the tower. During the day, the flow from the west is strong enough that plumes from the generator are rarely observed. At night the winds are weaker, and an occasional plume of short duration is observed. These data points can be identified by brief increases in total particle concentration and black carbon concentration.

\section{Aerosol Measurements:}

The physical properties of the aerosols at the site were measured using a variety of instruments. The optical properties of the aerosol were measured using an aethalometer (Model. AE2, McGee Scientific, Berkeley, CA) and an integrating nephelometer (NGN2, OPTEC, Inc, Michigan). An integrated measure of the number concentration of aerosols was provided by a condensation particle counter (CPC, TSI 3022A). Particle size distributions at the site were measured using an optical particle counter (Lasair 1003, Particle Measurement Systems) providing size distributions from 0.1 to $10 \mu \mathrm{m}$, and a scanning electrical mobility analyzer (SEMS) providing size distributions between 10 and $400 \mathrm{~nm}$. The SEMS system utilized a differential mobility analyzer (TSI 3071A) coupled with a CPC (TSI 3760) as a detector. All instruments except the OPC were mounted on the tower. The OPC was located in an adjacent instrument container. A schematic of the instrument placement on the tower is shown in Figure 2. The air was sampled at $16.7 \mathrm{~L}$ $\mathrm{min}^{-1}$ through a PM10 inlet followed by a PM2.5 sharp cut cyclone (Rupprecht \& Patashnick Co. models 57-000596 and 57-005896, respectively). The inlet was mounted above the top of the tower at a height of approximately $13 \mathrm{~m}$. Sample flows for the aethalometer, CPC, SEMS, and OPC were isokinetically sampled from this main flow. Measurements were recorded from 9 May to 14 November in 2002. Measurements from the CPC, SEMS, OPC, and nephelometer were recorded every 2 minutes, while those from the aethalometer were recorded every 5 minutes.

The aethalometer measures light absorption of the aerosol, $\mathrm{b}_{\mathrm{abs}}$, using a filter-based light transmission technique. (Hansen 1984) The instrument measures decreases in transmitted light through an increasingly particle-laden filter. Black carbon (BC) is the insoluble, most resistant to heating, graphitic, and strongly light absorbing component of the aerosol mass. The aethalometer used for this study measured light absorption at two wavelengths, $880 \mathrm{~nm}$ (near IR) and $350 \mathrm{~nm}$ (near UV). BC is believed to be the only aerosol component that absorbs in the near infrared spectral region, so measured transmission of $880 \mathrm{~nm}$ wavelength light is used to determine BC concentration. An empirically derived calibration equation is used to estimate the mass concentration of BC in air (in $\mu \mathrm{g} \mathrm{m}^{-3}$ ) from the measured decrease in light transmission. (Gundel et al. 1984) Blue and near ultraviolet light transmission measurements are used to indicate the presence of aerosol materials that absorb in these spectral regions, such as mineral dust (d'Almeida, 1987) and some types of organic compounds. (Kirchstetter, 2004; Bond, 2001) The flow rate through the instrument was $4 \mathrm{~L} \mathrm{~min}^{-1}$. 


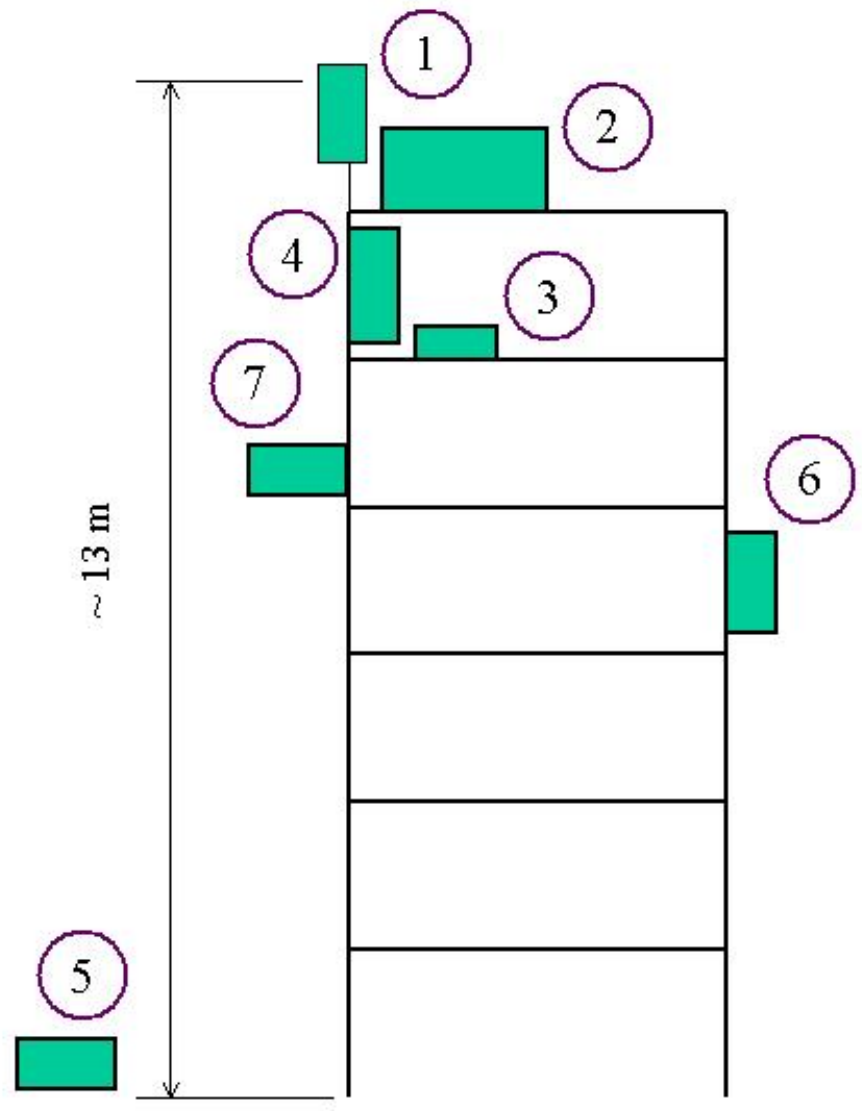

Figure 2: Schematic of the aerosol instrument on the tower. The instruments are as indicated: (1) $2.5 \mathrm{~mm}$ cyclone inlet, (2) aethalometer, (3) condensation particle counter, (4) scanning mobility particle scanner, (5) optical particle sizer, (6) nephelometer, and (7) filter samplers.

The nephelometer measures the light scattering coefficient, $b_{\text {scat, }}$ at an effective wavelength of $550 \mathrm{~nm}$. The instrument, described in more detail by Molenar et al. (1989), has an open air design, allowing the air to pass through a large opening in the side of the instrument. This design minimizes the changes in relative humidity and temperature that has lead to underestimated scattering measurements in other nephelometers. Because the instrument is open, it allows a wide range of particle sizes to pass through it, including particles $>2.5 \mu \mathrm{m}$. The cutpoint of the instrument has not been characterized.

The SEMS system provides aerosol size distributions using a mobility classifier. Particles are classified by their electrical mobility while moving across an electric potential. Only particles of a certain mass to charge ratio can exit the instrument. Particles exiting the instrument are counted using the condensation particle counter. By ramping over the voltage range of the instrument exponentially, it is possible to obtain size distributions relatively rapidly. (Wang and Flagan 1990) The SEMS system at the Blodgett field locations sampled aerosol at a flow rate of $0.7 \mathrm{~L}$ min-1. Utilizing a sheath flow rate in the mobility classifier of $7 \mathrm{~L}$ min-1, a full voltage scan of the instrument resulted in size distributions from $10 \mathrm{~nm}$ to $400 \mathrm{~nm}$. The SEMS system was controlled 
using Labview software and National Instruments control boards. One complete size distributions was obtained in a little over 1 minute using software developed by Donald Collins of Texas A\&M University and Patrick Chuang of the Univeristy of California at Santa Cruz. The inversion program used to process the raw data was based on that presented by Collins et al. (2002).

Size distributions of larger particles were provided by an optical particle counter. The instrument sized particles by measuring the amount of light that each individual particle scatters, and divides the measured size distribution up into 8 size bins between $0.1 \mu \mathrm{m}$ and $10 \mu \mathrm{m}$. The particular instrument employed was sensitive to temperature fluctuations, and was therefore housed in the temperature controlled instrument container where the other gas phase measurement systems were conducted. The aerosol was drawn from the sampling system down into the container by a 1/8” copper line. Sampling line losses were characterized on site for each size bin and averaged around 50 percent.

Aerosol measurements at the site have been ongoing since the fall of 2000, with the instruments operating primarily from late spring into late fall. The instruments vary a great deal in their ease of operation and degree of sensitivity to operating in the field. This has affected the quantity and availability of data for each instrument. Table I lists the dates that each instrument operated for each year at Blodgett.

Table I: Dates of operation for each aerosol instrument used at the Blodgett Field Site.

\begin{tabular}{|l|l|l|l|l|}
\hline & \multicolumn{1}{|c|}{2000} & \multicolumn{1}{c|}{2001} & \multicolumn{1}{c|}{2002} & \multicolumn{1}{c|}{2003} \\
\hline \hline CPC & $10 / 5-11 / 21$ & $7 / 12-10 / 20$ & $5 / 9-11 / 13$ & $8 / 6-$ present \\
\hline Nephelometer & $10 / 5-11 / 11$ & $7 / 12-11 / 5$ & $5 / 9-11 / 13$ & $8 / 6-$ present \\
\hline Aethalometer & $9 / 28-11 / 21$ & $7 / 12-10 / 24$ & $5 / 9-11 / 12$ & $6 / 23-$ present \\
\hline SEMS & N/A & $7 / 12-10 / 24 *$ & $5 / 29-11 / 13$ & $7 / 31-11 / 19$ \\
\hline Lasair & N/A** & N/A & $5 / 9-11 / 13$ & N/A \\
\hline
\end{tabular}

*The SEMS was not functioning correctly for much of the 2001 measurement season due to a noise problem in the signal lines. This problem was not identified and corrected until September, 2001.

** The Lasair proved to be extremely sensitive to temperature, and measurements were not successful until we installed it in the temperature controlled container.

During the late summer and fall of 2003, a semi-regular set of filter samples was collected to provide measures of PM2.5 mass as well as carbon, nitrate, sulfate, and ammonium through chemical analysis. These filter measurements provide important data concerning the chemical composition of the aerosol, including what fraction is organic, and important quantity that affects the partitioning coefficient (Eq. 8). Each measurement period consisted of four sets of samples collected over 48 hours, with the filter samples running from 9:30 AM to 7:30 PM, and from 8 PM to 9 AM. The times during which the filters were changed correspond to periods when the wind was shifting downslope to upslope in the morning and upslope to downslope in the evening. This results in particle chemistry at the site during periods of primarily anthropogenic emissions and primarily biogenic. The first sample line consisted of a NaCl coated honeycomb denuder followed by a $25 \mathrm{~mm}$ Teflon filter (Gelman), and then one $47 \mathrm{~mm}$ Nylon filter (Gelman) and a cellulose fiber filters (Whatman) in a Teflon filter holder 
(Savillex). The nylon filter was analyzed for gaseous nitric acid. The cellulose filter was impregnated with citric acid to allow for the analysis of gaseous ammonia. (Anlauf et al. 1988) The second sampling line used dual $25 \mathrm{~mm}$ diameter quartz filters operated in series for total and organic carbon concentrations. The third sampling line was similar to the second, consisting of a $25 \mathrm{~mm}$ Teflon filter (Gelman) followed by a $25 \mathrm{~mm}$ quartz filter. This third line was used to quantify the organic sampling artifact (cite Kirchstetter et al. 2001, Turpin et al. 1994). All three lines drew a sample through a different inlet than that used by the aerosol instrumentation. Each line employed a 2.5 $\mu \mathrm{m}$ cyclone precut (John and Reischl 1980) and was sampled at a flow rate of approximately $25 \mathrm{~L} / \mathrm{min}$.

PM2.5 mass was gravimetrically determined using a Cahn Model 21 electro-balance. Before weighing, the Teflon filters were equilibrated for at least 4 hours at $20^{\circ} \mathrm{C}$ and a relative humidity of $35 \%$. For chemical analysis, the filters were extracted by sonication in distilled deionized water. Extracts from both the Teflon filters were analyzed for nitrate and sulfate by ion chromatography and for ammonium by an ion-specific (ammonia gas-sensing) electrode. The nylon filters were analyzed by ion chromatography. The citric acid impregnated cellulose fiber filters were analyzed for ammonium ion by an ion-specific electrode. The quartz filters were assayed for carbon using the evolved gas analysis method of Novakov et al. $(1982,1983)$. The ambient organic carbon particulate was calculated as the difference between the values measured on the front and back filter.

A similar set of filter measurements was also performed in the late fall of 2002. During this period, a series of controlled burns was performed at other locations on the Blodgett property. These prescribed burns were performed by Scott Stephens and his group from the Department of Environmental Science, Policy, and Management at the University of California at Berkeley as part of a project to study fire and fire surrogates for forest restoration. Forest fires can be a significant source of organic aerosol, and can serve to reduce visibility over large regions. The air masses at the measurement tower were heavily impacted by the prescribed burns, resulting in an opportunity to sample and analyze the aerosol resulting from the fires.

\section{VOC Measurements:}

Continuous in-situ hydrocarbon measurements were taken at 1 hour intervals using a fully automated gas chromatograph dual flame ionization detector (GC-FID) system (Lamanna and Goldstein 1999). Air was sampled at $8 \mathrm{~L}$ min-1 through $2 \mu \mathrm{m}$ PTFE particulate filters and Teflon tubing and then subsampled at $20 \mathrm{~mL}$ min- 1 onto a graphitized carbon black and carbon molecular sieve preconcentration system packed in series and mounted in a cold block. After preconcentration, the samples were thermally desorbed $\left(\sim 250^{\circ} \mathrm{C}\right.$ for $\left.1.2 \mathrm{~min}\right)$ onto two Rtx-WAX columns for separation and quantification by the two FIDs. The system was fully automated (HP Chemstation and Campbell Scientific data logger) and processed as a 20 min average sample every hour. The experimental detection limit depended upon the species, but averaged 10-20 parts per trillion. Mixing ratios above $0.2 \mathrm{ppb}$ are considered accurate to $15 \%$. 
While gas chromatography has been a useful instrument to measure atmospheric concentrations of VOCs, the long time resolution of the technique limits its usefulness in the analysis of the dynamics of processes that occur on faster time scales. To enable gas phase measurements with higher time resolution, a proton-transfer-reaction mass spectrometer (PTR-MS) was employed at the site beginning July 2002. The PTR-MS utilizes chemical ionization for the analysis of trace constituents, with a VOC detection limit at the parts per trillion level and a time response of $\sim 0.2 \mathrm{~s}$. Because the measurements of the PTR-MS are based upon mass, the molecular weight of the target analyte must be unique. Thus the system can is used to measure the total concentration of monoterpenes because all monoterpene species share the same molecular weight. Similarly, the concentration of different groups of monoterpene oxidation products will be detected because many of the oxidation products of different monoterpenes have common molecular weights as well.

Table II: VOC species measured at the Blodgett forest field location by year. During 2002 and 2003 the species are grouped by instrument.

\begin{tabular}{|l|l|l|l|}
\hline \multicolumn{1}{|c|}{$\mathbf{2 0 0 0}$} & \multicolumn{1}{c|}{$\mathbf{2 0 0 2}$} & \multicolumn{1}{c|}{$\mathbf{2 0 0 3}$} \\
\hline alphapinene & Isoprene & GC: & GC: \\
\hline betapinene & Acetaldehyde & alphapinene & alphapinene \\
\hline Toluene & Acetone & betapinene & betapinene \\
\hline Isoprene & Butanol & 3-carene & 3-carene \\
\hline $\begin{array}{l}\text { Methylvinyl } \\
\text { ketone (MVK) }\end{array}$ & Methacrolein (MACR) & $\begin{array}{l}\text { Limonene + b- } \\
\text { phellendrene }\end{array}$ & $\begin{array}{l}\text { Limonene + b- } \\
\text { phellendrene }\end{array}$ \\
\hline methacrolein & Methyl furan & alphaterpinene & alphaterpinene \\
\hline 3-carene & Methanol & Camphene & Camphene \\
\hline & $\begin{array}{l}\text { Methylethyl ketone } \\
\text { (MEK) }\end{array}$ & Myrcene & Myrcene \\
\hline & Ethanol & & PTR-MS: \\
\hline & Benzene & Total monoterpene & Acetonitrile \\
\hline & MVK & Acetaldehyde & Isoprene + MBO \\
\hline & Pentanal & Acetone & Total monoterpene \\
\hline & alphapinene & MACR + MVK & Benzene \\
\hline & Toluene & Toluene & Toluene \\
\hline & $\begin{array}{l}\text { 2-methyl-3-buten-2-ol } \\
\text { (MBO) }\end{array}$ & Isoprene + MBO & Methyl chavicol \\
\hline & Camphene & 3-methylfuran & MACR + MVK \\
\hline & Hexenal & & Methanol \\
\hline & betapinene & & Acetone \\
\hline & 3-Carene & Nopinone \\
\hline & Myrcene & Pinonaldehyde \\
\hline & o-xylene & & \\
\hline & limonene & & \\
\hline & & & \\
\hline
\end{tabular}


The VOC measurements at the site have been ongoing since 1997, and have been performed by Allen Goldstein and his group in the Department of Environmental Science, Policy and Management at the University of California at Berkeley. Table II lists the individual VOC species that have been measured in each year that aerosol data is available. Their research has been supported by the California Air Resources Board (CARB) and the National Science Foundation (NSF).

\section{NOy Measuremements:}

A system utilizing thermal dissociation at several specific temperatures and catalytic oxidation coupled with laser induced fluorescence of $\mathrm{NO}_{2}$ was used for in situ measurements of the important nitrogen containing trace gas systems in the atmosphere. The gases measured included $\mathrm{NO}, \mathrm{NO}_{2}$, the sum total of peroxy nitrates, the sum total of alkyl nitrates and hydroxyalkyl nitrates, and nitric acid. The instrument is capable of

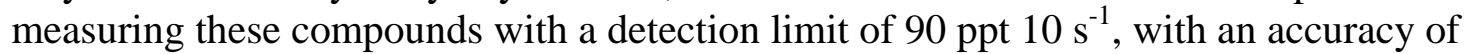
$15 \%$. Ronald Cohen and his group from the Chemistry Department at the University of California at Berkeley conducted the measurements.

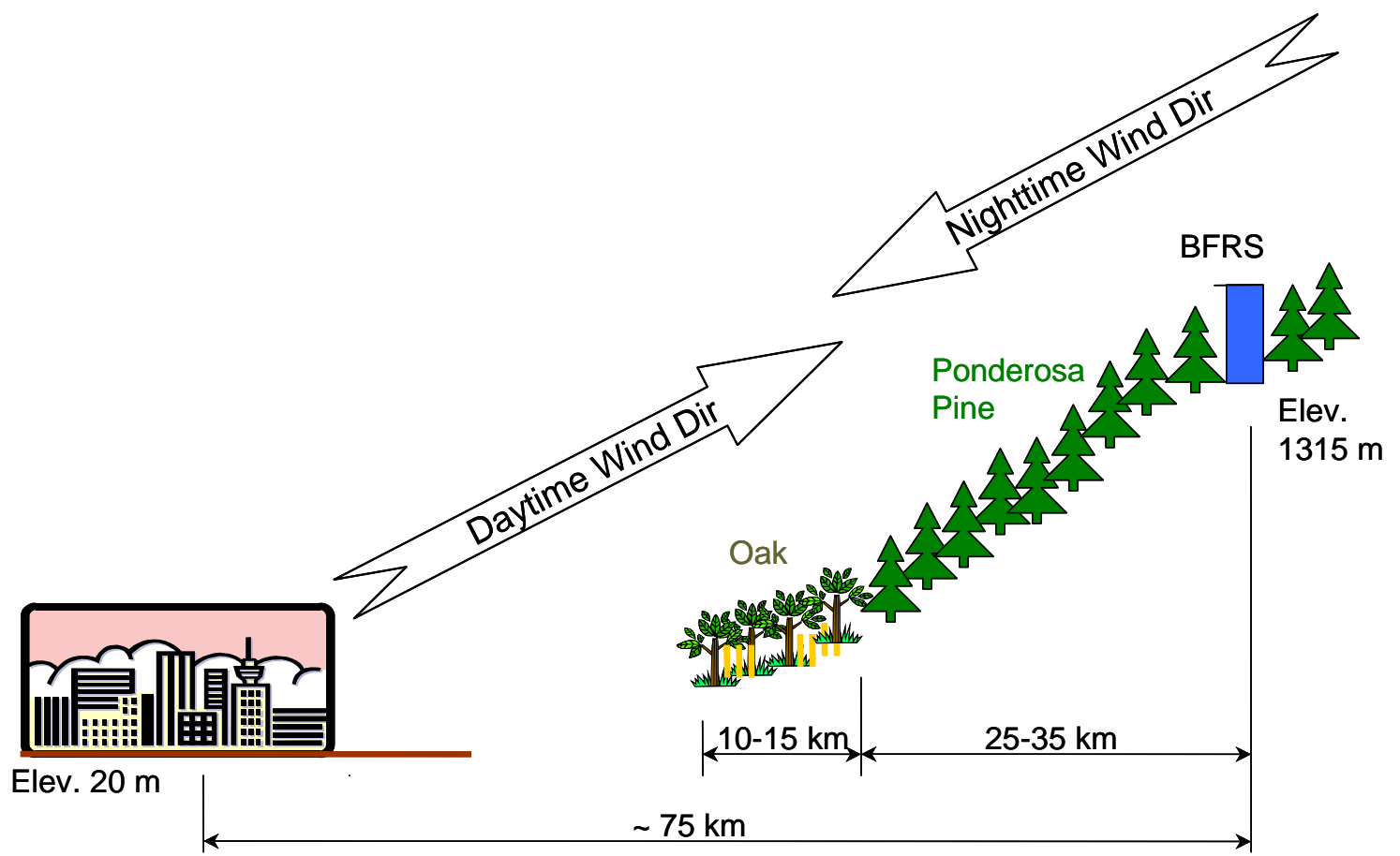

Figure 3: A diagram of the wind patterns experienced by the Blodgett Forest research tower. 


\section{Meteorological and other measurements:}

Meteorological parameters such as air temperature, humidity, wind speed and direction, and net and photosynthetically active radiation (PAR) were measured continuously and stored as 30-minute averages. Meteorological data and trace gas mixing ratios and fluxes $\left(\mathrm{CO}_{2}, \mathrm{H}_{2} \mathrm{O}, \mathrm{O}_{3}\right.$, and hydrocarbons) were measured approximately 5-6 $\mathrm{m}$ above the average tree height.

\section{Results and Discussion}

Aerosol data exist for the Blodgett field location for the years 2000, 2001, and 2002. Support from LBNL-Laboratory Directed Research and Development Funds was used to initiate the particle measurements in 2000, and was continued with support from the California Air Resources Board during 2001 and 2002. The data from 2000 was obtained for a limited number of weeks, and contains no size resolved data. However, VOC measurements are available from the Goldstein group for 2000, and therefore we performed some preliminary correlations between the aerosol and VOC measurements with this data. The aerosol measurements were expanded in 2001, however it appears that it may be some time before the VOC data from this year will be available. Therefore, much of the results that we will present in this report are from the 2002 data set. This data set is the most complete, with integrated and size resolved data as well as measured optical properties for a number of months. This data has been analyzed to identify any inconsistencies, biases, or artifacts, and periods of faulty instrument performance were removed to bring it to Level I readiness. The VOC data from 2002 is currently being processed and some subsets of the data will be available soon.

An important final task necessary for more sophisticated data analysis to proceed is to remove the signal resulting from generator plumes from the data. As noted previously, during the evening when the winds are weak, plumes of particulate emissions from the generator can be observed in the particulate data. Diesel generators often emit large concentrations of small $(<100 \mathrm{~nm})$ carbonaceous particles. These emissions are reflected in the data by brief increases in total particle and black carbon concentrations, as well as the appearance of a smaller mode in the size distributions. We are currently pursuing several routes to remove this diesel signal from the data. We have obtained data from the sonic anemometer that provides data on wind speed and wind direction at one-minute time intervals, and are testing to see if the spike occurs when the wind direction is from the same direction as the generator. By combining this data set with black carbon and size resolved measurements, we can more precisely identify times that are affected by the generator. Lastly, we are developing data rejection routines that can test for quick, short, large-scale departures from any individual data set that are due to the generator. By using these techniques alone or in combination, we will have a good data rejection criterion to bring the particle data to Level II readiness. 


\section{Meteorology, pollutant formation and transport:}

The predominant daytime airmass trajectory at the site is southwest, directed upslope from the Sacramento Valley. At night, air flows northeast, downslope from the Sierra Nevada Mountains. Figure 3 shows this diurnal wind pattern graphically. During the daytime, the upslope flow brings pollution to the site that is a mixture of urban outflow from the Bay Area and Sacramento and agricultural outflow upwind of Sacramento. During the evening the downslope drainage flow from the mountains brings cleaner air containing primarily biogenic emissions.

The effect of the diurnal wind patterns at the measurement tower on transport of anthropogenic pollutants to the site are shown in Figure 4. The top graph shows how the wind direction shifts from downslope to upslope flow between 7 and 9 AM, and shifts back again between 6 and $8 \mathrm{PM}$. The bottom plot shows the typical pattern in total particle concentration. The concentration begins to rise in the afternoon as pollutants are transported to the tower location. The concentration decreases after the wind shifts to cleaner downslope flow from the Sierras. Figure 4 also shows the effect of the generator that provides power to the site on the particle measurements.

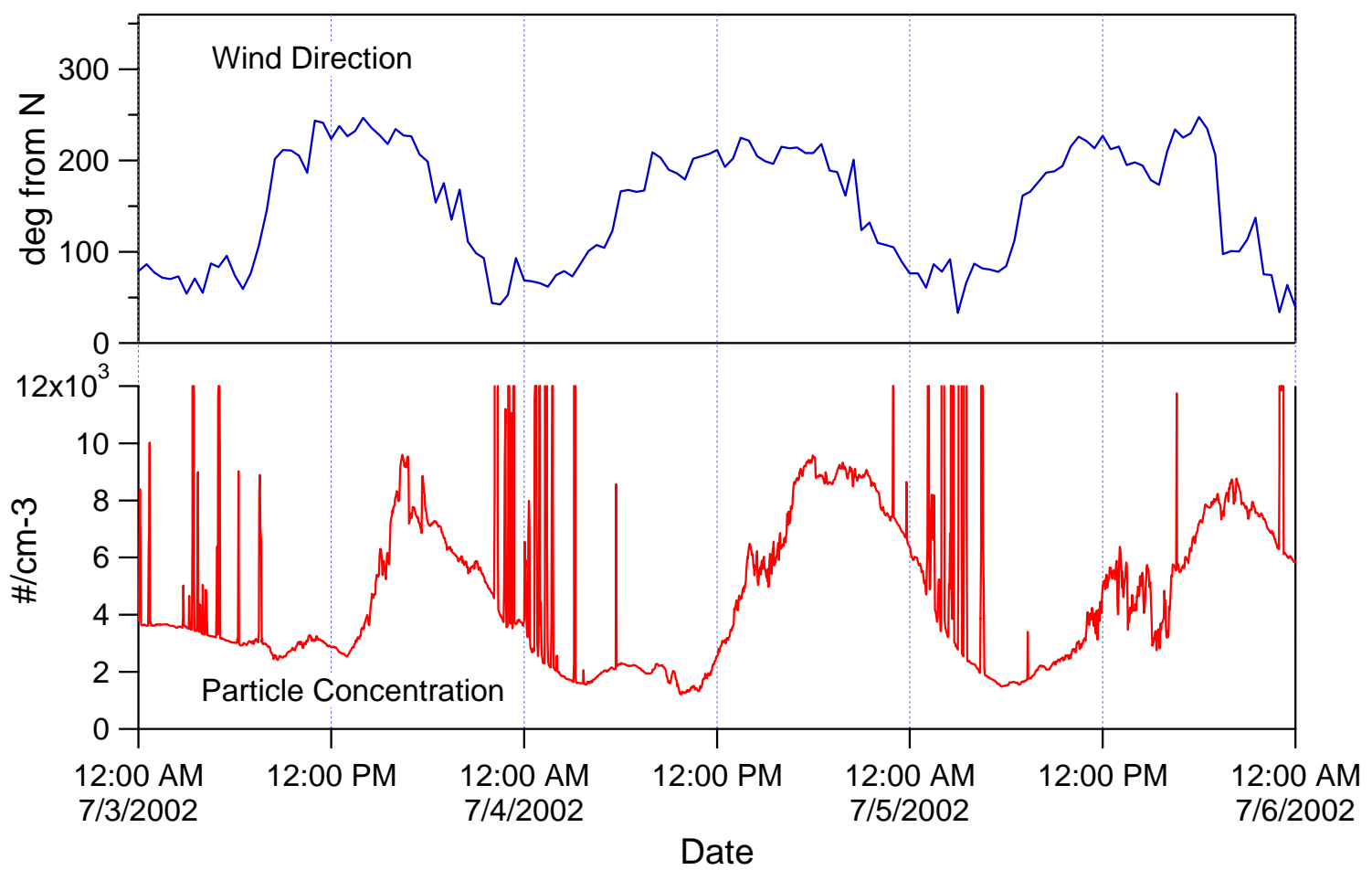

Figure 4: Wind direction and particle concentration data measured at the Blodgett tower for a three day period in July of 2002.

Typical patterns in the VOC concentrations measured at the tower during the year 2000 are shown in Figure 5. Isoprene, a reactive VOC emitted from oaks, has maximum concentrations in the afternoon and minimum in the early morning. Toluene, an anthropogenic compound, increases rapidly around noon after the wind shifts direction and increases in speed, and remains high until cleaner air descends from above. 
Terpenes, represented by alpha-pinene, have a diurnal pattern with highest concentrations at night when vertical mixing is weakest and low concentrations during the day when mixing is more vigorous.
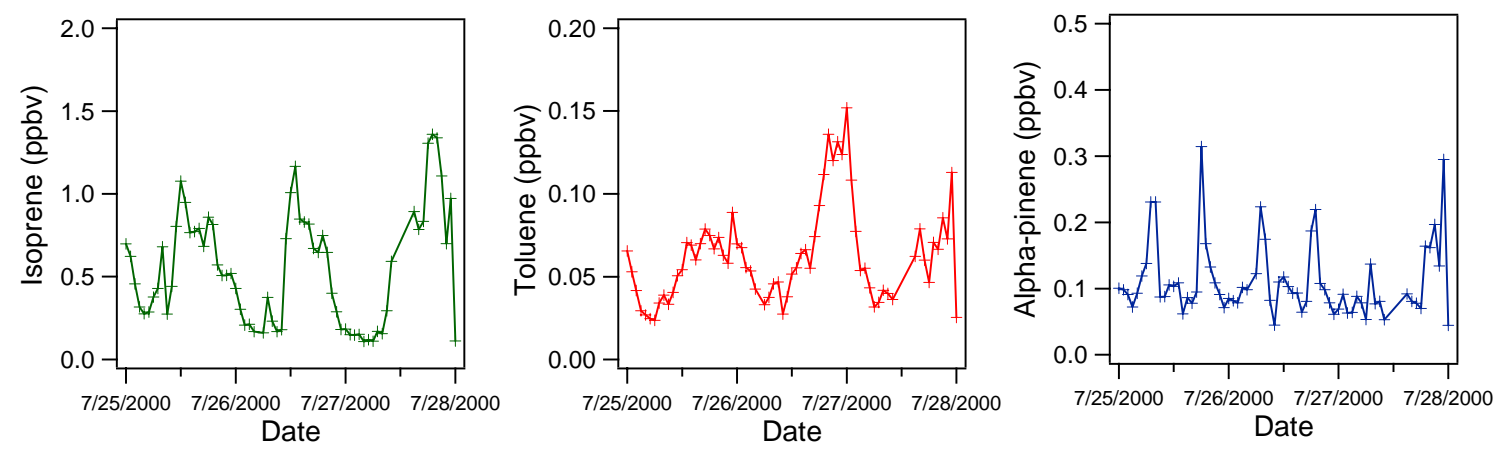

Figure 5: Typical diurnal patterns of the three important VOC species measured during 2000: (a) isoprene, (b) toluene, and (c) alpha-pinene.

Half hour averages of total particle concentration measured with the CPC and black carbon concentrations measured using the aethalometer were analyzed with the VOC data from the year 2000 to look for correlations between different types of organic precursors and particle loading. The results of the correlations between particle and VOC concentrations are shown in Table 3. The results show correlation with both biogenic and anthropogenic (toluene) precursors, implying that aerosol at the site result from a mix of sources. The correlation with the biogenic VOCs a-pinene and b-pinene that are emitted by the pines are relatively weak. The correlation with isoprene, emitted by oak trees, is stronger and is accompanied by strong correlations with the oxidation products of isoprene (MVK and methacrolein), implying that oxidation of oak emissions upstream are contributing to the particle load at the tower.

Table III: Results of multivariate correlations between total particle concentration and VOC concentration. Note that these correlations are for 422 hours of complete data from the fall of 2000.

\begin{tabular}{|c|c|}
\hline Gas Phase Compound & Correlation \\
\hline \hline$\alpha$-pinene & 0.14 \\
\hline$\beta$-pinene & 0.15 \\
\hline Toluene & 0.56 \\
\hline Isoprene & 0.38 \\
\hline Methyl vinly ketone & 0.45 \\
\hline methacrolein & 0.39 \\
\hline
\end{tabular}

Black carbon and carbon monoxide both serve as excellent tracers of anthropogenic emissions as they primarily result from combustion. The correlation between particle concentration and black carbon was 0.69 , and the correlation with carbon monoxide was 0.73. These correlations, combined with the correlation with toluene, imply that the total particle loading at the site is associated with anthropogenic emissions transported to the site from the Sacramento Valley. The results, however, do not definitively demonstrate 
that the aerosol at the site results from anthropogenic sources; the urban outflow may simply be arriving at the site on the same time frame that other local biogenic processes are simultaneously contributing to the particle load.

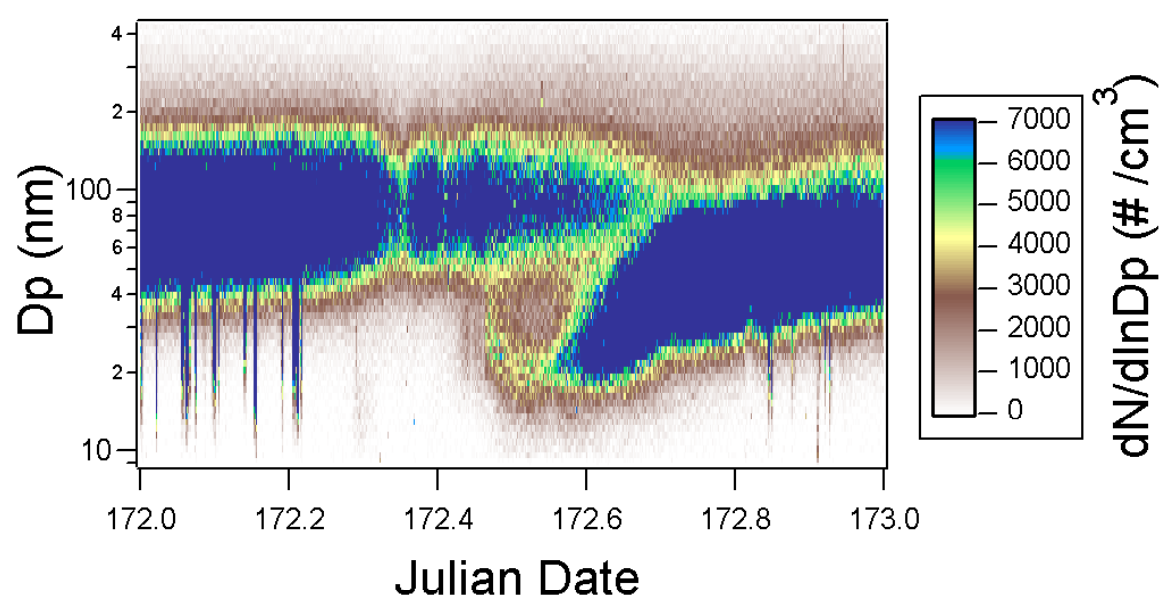

Figure 6a: A time line of the size distribution at the Blodgett Forest field location for 21 June, 2002.

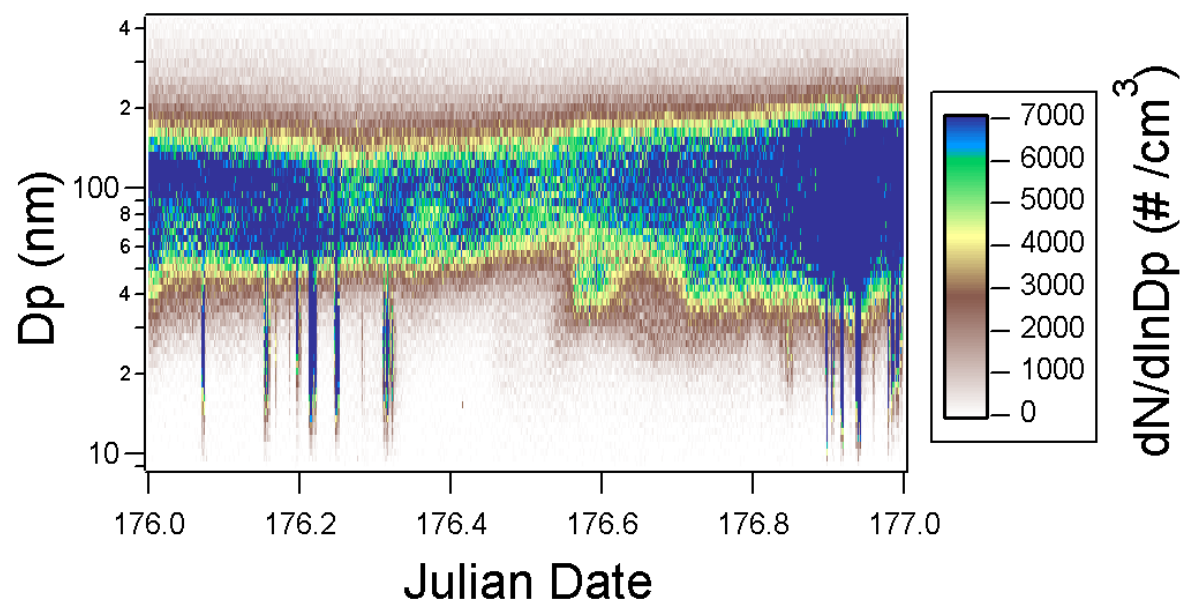

Figure 6b: A time line of the size distribution at the Blodgett Forest field location for 25 June, 2002.

Particle formation and growth:

The size distribution measurements performed at the tower site during 2002 provide important additional information about the nature of the aerosol that cannot be ascertained from measures of total concentration alone. An important feature of atmospheric aerosol distributions is the fact that they often exhibit multiple modes. 
Particles of size with an aerodyamic diameter, $\mathrm{D}_{\mathrm{p}}$, greater than approximately $1 \mu \mathrm{m}$ are often referred to as the coarse mode. These particles are generated by mechanical processes, and consist of soil dust, sea salt, tire and break wear particles, etc. Fine mode is the term for particles of size less than $1 \mu \mathrm{m}$; fine mode particles contain particles from combustion sources, and secondary aerosols formed by chemical reactions that result in gas-to-particle conversion. The fine mode can be further divided into an accumulation mode $\left(0.1 \mu \mathrm{m}<\mathrm{D}_{\mathrm{p}}<1.0 \mu \mathrm{m}\right)$ and a nuclei mode $\left(\mathrm{D}_{\mathrm{p}}<0.1 \mu \mathrm{m}\right)$. The primary mechanism for movement of particles from the nuclei to the accumulation mode is by coagulation and growth by condensation of vapors onto existing particles. Coagulation among accumulation mode particles is slow and does not result in growth into the coarse mode. It should be noted that the size boundaries between these different sections are not precise, and depend on the type of region (urban, remote, marine etc.) in which the aerosol exists.

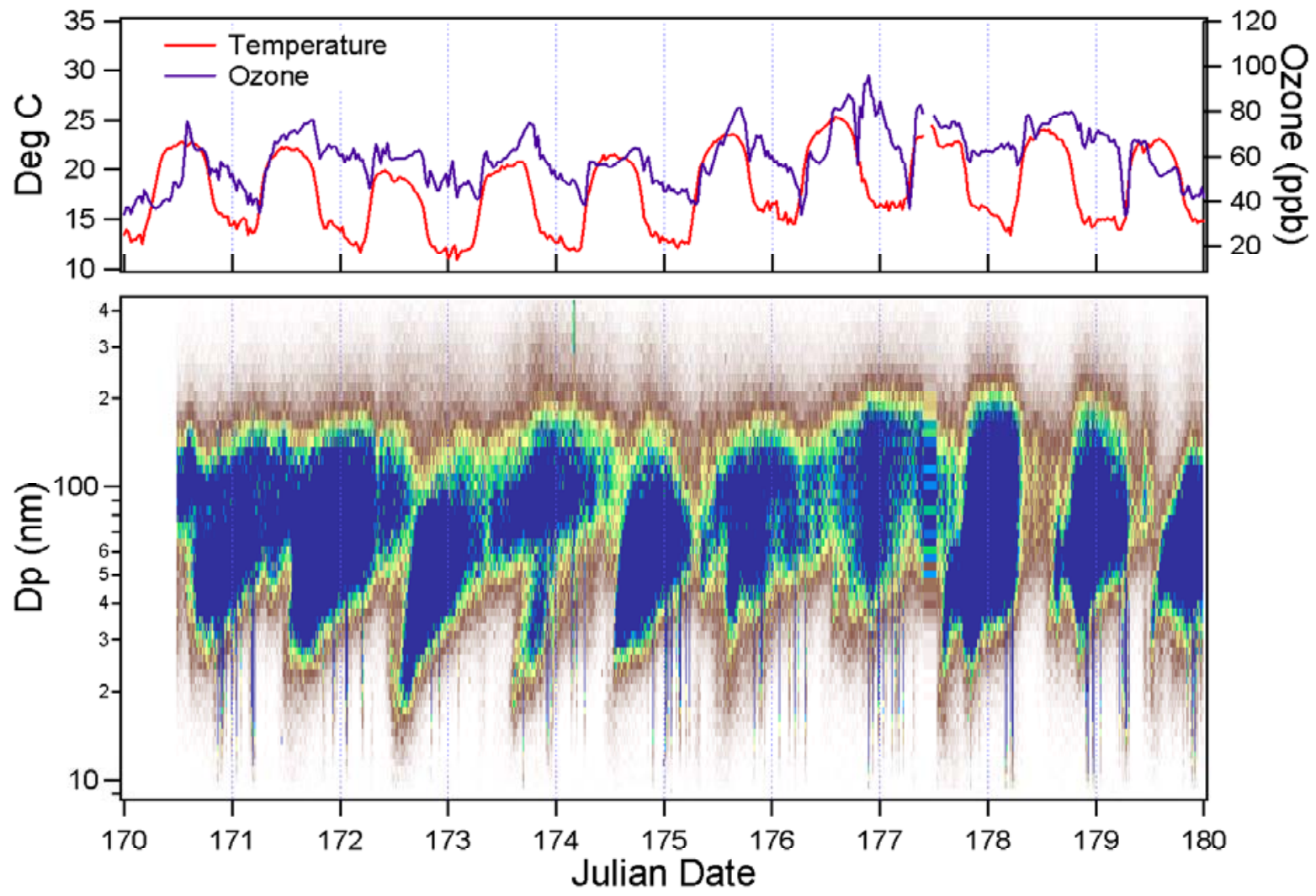

Figure 7: Time resolved evolution of the aerosol size distribution from 19 June to 29 June 2002. The upper plot shows the temperature (on the left axis) and ozone (on the right axis) data for the time period.

Aerosol size distributions in rural locations do not always contain particles in the nuclei mode. The accumulation mode provides a significant surface area for condensable gases to partition onto. Nuclei mode particles will form only when there is a sufficiently large concentration of condensable gases for it to be thermodynamically favorable for new particles to form. The size to which these particles grow depends upon the amount of 
material available for condensation and the degree to which these particles absorb water. Particles that are quite small, $50 \mathrm{~nm}$ or less in size, do not have long lifetimes in the atmosphere. Their small size and thus enhanced diffusional mobility lead to scavenging by larger particles and deposition to surfaces. Therefore, when such small particles exist, it can be concluded that they were formed from gas phase precursors relatively close to the measurement location.

A time history of the particle size distribution of two separate days at the Blodgett forest location are shown in Figure 6. The figure shows each two-minute size distribution vertically, with color representing the number concentration at each measured diameter. From midnight until midday, the peak of both size distributions is around $100 \mathrm{~nm}$. The particles in this mode are likely a mixture of sulfates, nitrates, and black carbon formed by atmospheric processing of pollutants transported from upstream and local emissions sources. Note that in Figure 6a, a smaller size mode of aerosol begins to appear just after noon. These nuclei mode particles, initially below $20 \mathrm{~nm}$ have a limited lifetime in the atmosphere $(\sim 1 \mathrm{hr})$, suggesting local formation mechanisms. Figure $6 \mathrm{~b}$ shows a day when such a growth event does not occur.

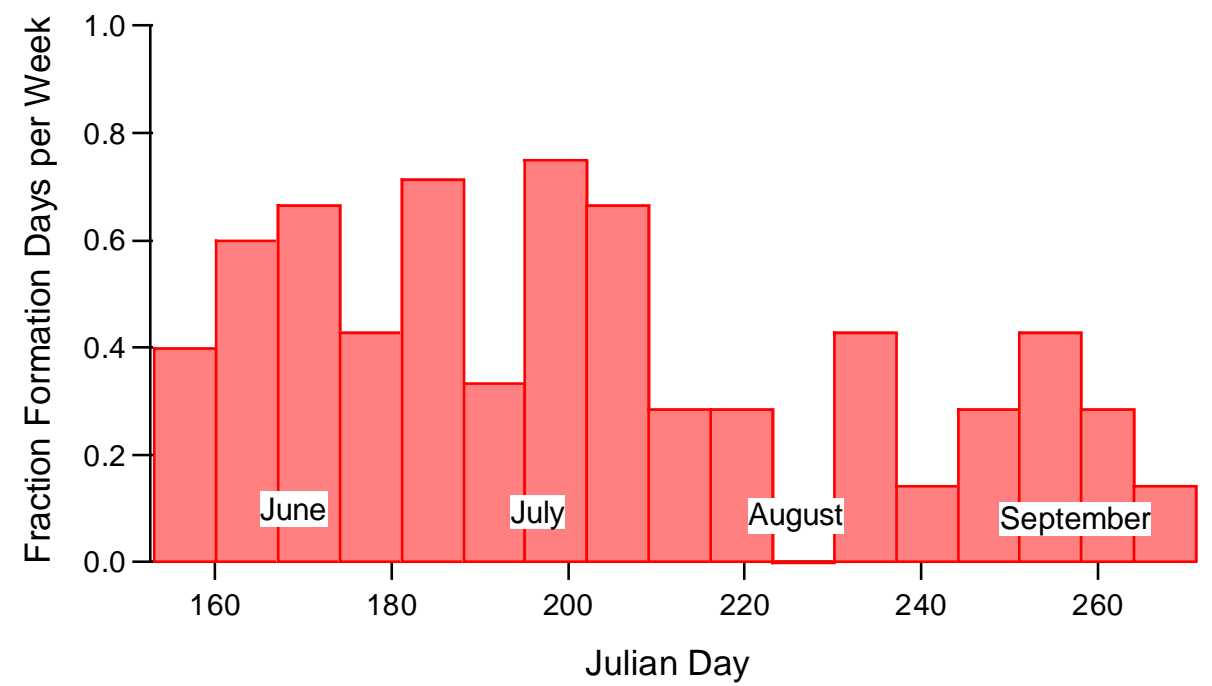

Figure 8: The fraction of days per week that a growth event occurred for the months of June through September.

Figure 7 shows a time line of 10 days from 19 June to 29 June, 2002. During this week, it appears that the fine particle growth events happen on 7 of the 10 days. The lifetime of $20 \mathrm{~nm}$ sized particles in the atmosphere is approximately 1 hour. Combining typical wind speeds and the size of the forest results in transport times within the forest that are greater that this lifetime, implying that the particle growth events occur over the forest. These particles are formed either from a combination of biogenic processing of the anthropogenic air mass or solely by biogenic reactions. Figure 8 shows the fraction of days each week that these growth events occurred for the months of June through September. Most weeks had a significant fraction of days with these formation events. Observations by other investigators at other locations have suggested that particle 
formation events are preceded by a period of relatively particle-free air. In contrast, we have observed formation both with and without the presence of a larger aerosol mode.

A detailed look at the aerosol size distributions before, during, and after the appearance of the nuclei mode aerosol is shown in Figure 9 for July 24, 2002. At 11:45, the size distribution is peaked at approximately $80 \mathrm{~nm}$. The appearance of the nuclei mode can be clearly seen in Figure 9b at approximately $25 \mathrm{~nm}$, with the primary accumulation mode peak still at $80 \mathrm{~nm}$. By the early evening, the nuclei mode has continued to grow by condensation of more gas phase product, and the particles in the smaller mode have been coagulating with those in the larger mode. This results in the broader distribution, seen in Figure 9c, where the nuclei and accumulation modes have almost merged, although the nuclei mode peak can still be discerned at approximately $45 \mathrm{~nm}$.

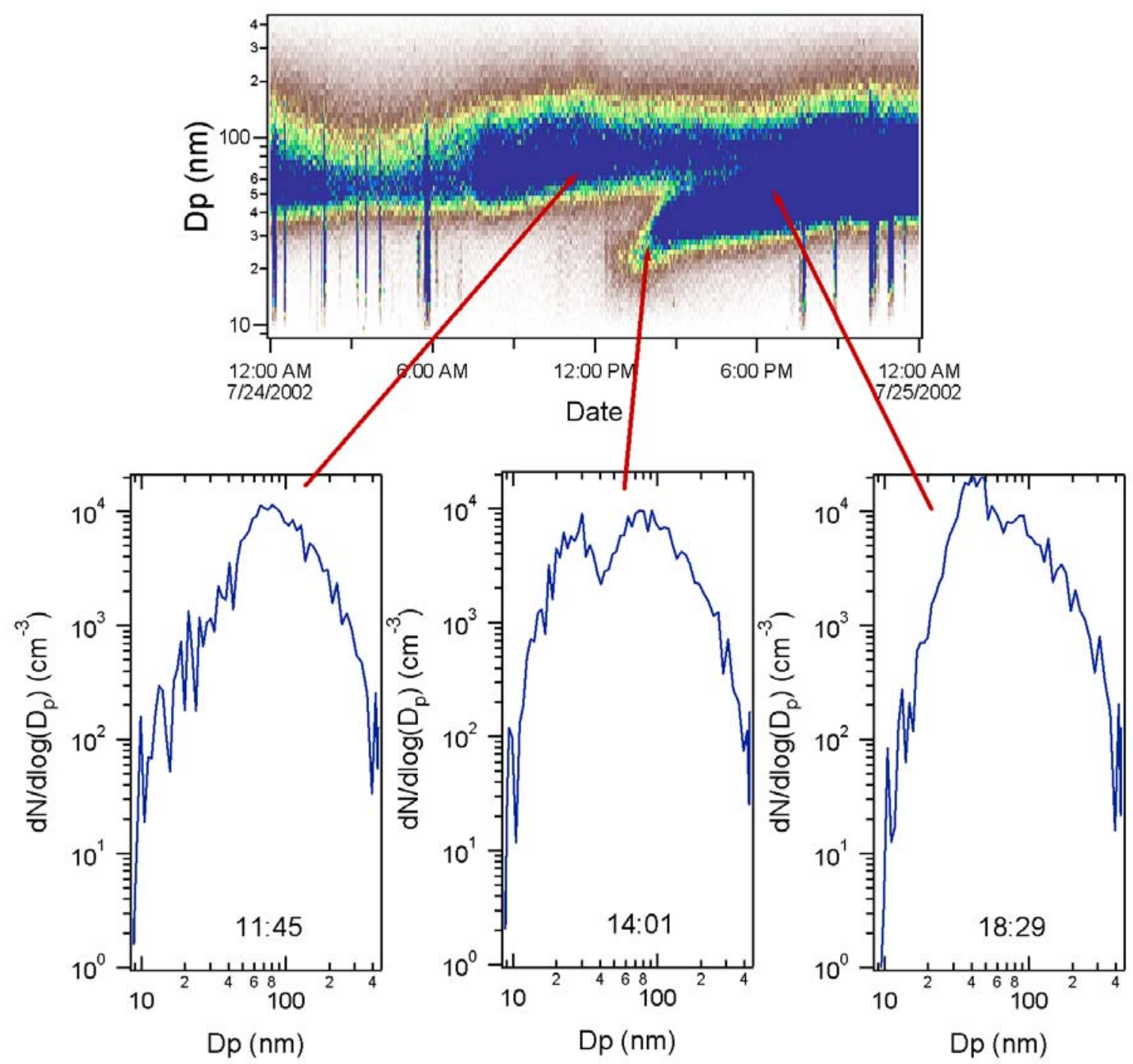

Figure 9: Aerosol size distributions (a) before, (b) during, and (c) after the particle growth event measured on July 24, 2002. 
The growth events seen in the size distribution data provide evidence for the physical processes that lead to particle formation and growth. As discussed previously, when the concentration of condensable gases increase, they have two routes to the particle phase; they may nucleate to form new particles or condense onto existing particle surface area. The route to condensation depends upon the thermodynamics of both the gas and particle phases. At the Blodgett site, the oxidation products will most often condense onto accumulation mode particles. Arguments using thermodynamics suggest that low volatility products resulting from the oxidation of biogenic VOC's are not likely to nucleate. It does appear that new particles are being formed during these particle growth events. It has been suggested that these nuclei mode particles are instead growing by condensation onto pre-existing, very small "seed" particles $(<3 \mathrm{~nm})$ that likely consist of sulfuric acid. (Czoschke et al 2003) There is, however, reason to believe that the majority of the mass addition in these growth mode particles is due to condensed organic oxidation products.

There is some experimental evidence available to provide an explanation for what conditions lead to the occurrence of the growth events. Among the factors that affect when and to what extent the organic oxidation products partition to the particle phase are the gas phase concentration of condensable products, the rate at which the gas accumulates, the concentration of seed particles, and the temperature and relative humidity of the ambient environment. An important variable is temperature. Recall that in Eq. 7 that the partitioning coefficient, $K_{p, i}$, is inversely proportional to the vapor pressure of the absorbing compound. As the temperature decreases, the vapor pressure also decreases, thereby increasing the partitioning coefficient. When the temperature is reduced, the oxidation products are more likely to partition to the aerosol phase, however it is also possible that fewer oxidation products form. These two competing processes, the increase in partitioning and decrease in reaction rates, suggest that optimum conditions for the temperature at which growth events occur are rather sharply defined.

The effect of temperature can be observed in Figure 7, which shows time resolved temperature and ozone measurements recorded for the same time period at the aerosol size distributions. The figure shows that when the temperature is higher, the particle growth events are less likely to occur. This is evidenced in the difference between day 172 , one of the colder days during this 10-day period and with a pronounced growth event versus day 176, the warmest day of this period with no discernable growth in the nuclei mode. A summary of this phenomenon for the summer months can be seen in Table 4, which gives the daily maximum temperature for the days with and without growth events. The days with growth events had a maximum temperature approximately $4{ }^{\circ} \mathrm{C}$ lower than days with no events.

Table IV: Average maximum daily temperature for days in 2002 on which growth events occurred and those with no event.

\begin{tabular}{|l|c|c|c|c|}
\hline & June & July & Aug & Sept \\
\hline \hline Growth Event & $21.1^{\circ} \mathrm{C}$ & $24.3^{\circ} \mathrm{C}$ & $23.0^{\circ} \mathrm{C}$ & $21.7^{\circ} \mathrm{C}$ \\
\hline No Event & $25.0^{\circ} \mathrm{C}$ & $28.0^{\circ} \mathrm{C}$ & $26.5^{\circ} \mathrm{C}$ & $24.8^{\circ} \mathrm{C}$ \\
\hline
\end{tabular}


Figure 10 shows the same series of size distribution data shown in Figure 7, as well as several integrated quantities calculated from the size distribution: total number concentration, total particle volume, and particle volume less than $50 \mathrm{~nm}$. It is not shown here, but the total particle concentration calculated from the size distribution data matches well with that measured by the CPC. The total calculated particle volume is between 1 and $10 \mu \mathrm{m}^{-3} \mathrm{~cm}^{-3}$, and does not vary over the same dynamic range that total particle number does. This is due to the fact that particle volume, being the cube of particle diameter, is more sensitive to larger particles. The behavior of the particle volume calculated for particles smaller than $50 \mathrm{~nm}$ looks very similar to the time resolved behavior of total particle concentration. Thus, total particle number is often dominated by smaller sizes, particularly on days with particle growth events, when large numbers of small particles exist.
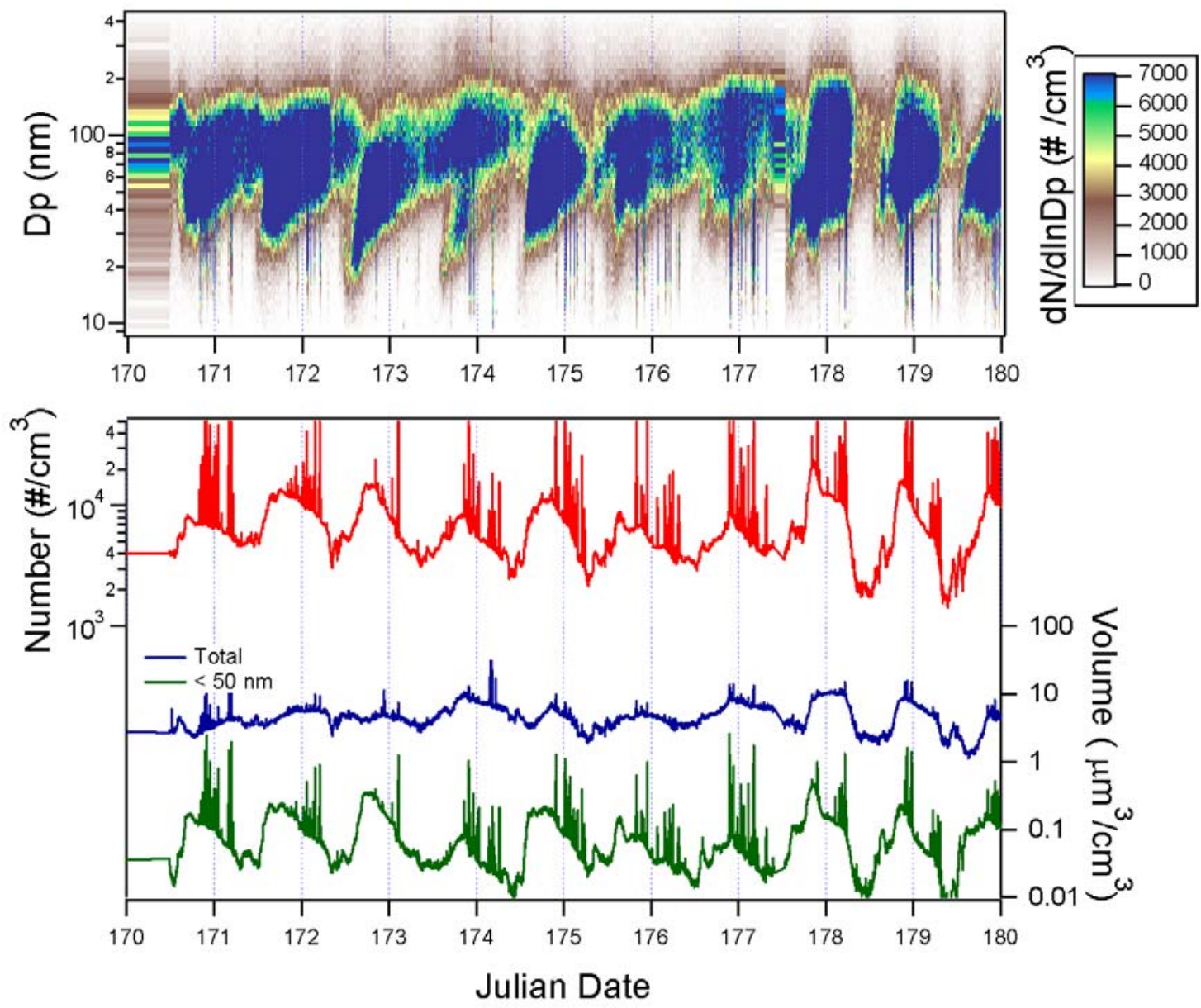

Figure 10: The upper plot shows the time resolved evolution of the aerosol size distribution from 19 June to 29 June 2002. The lower plot shows the total particle number, particle volume, and particle volume for those particles less than $50 \mathrm{~nm}$ calculated from the size distribution data. 
The percentage of total particle volume that is contributed by particles less than $50 \mathrm{~nm}$ in size is shown in Figure 11 calculated from the same size distribution data shown in Figure 10. In general, the percentage of total particle volume contributed by particles less than $50 \mathrm{~nm}$ is quite small, around 1 percent. However, during the growth events in the nuclei mode, the fraction of total particle volume from this size range can increase to as high as 10 percent. This is a significant fraction, particularly if it consists primarily of biogenic organic oxidation products. The fate for the majority of these nucleation mode particles is coagulation with the larger particle mode. Consequently, the processing of these small particles via coagulation with larger ones can be a significant pathway of SOA into the ambient aerosol.

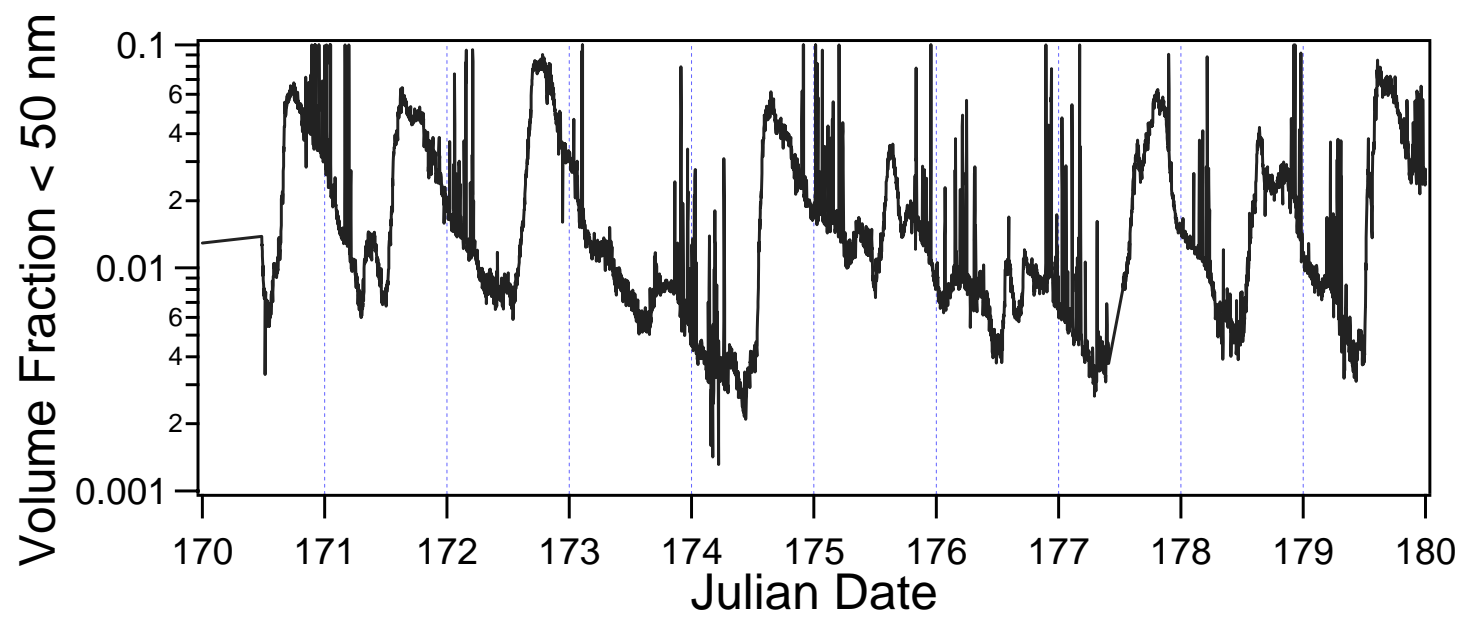

Figure 11: Fraction of total particle volume for those particles less than $50 \mathrm{~nm}$ calculated from the size distribution shown in Figure 10.

To further explore the link between secondary oxidation products and condensation onto the nucleation mode particles, we next focus on the total particle mass in the nuclei mode to ascertain whether this mass is of the same order of magnitude as the measured concentration of oxidation products. Figure 12 shows the mass calculated for particles less than $50 \mathrm{~nm}$. This calculation assumes that the particles are entirely organic with a molecular weight of 136, equivalent to that of a monoterpene. The units have been converted into ppb for ease of comparison with gas phase data. The results show that the calculated mass is between 0.005 and $0.1 \mathrm{ppb}$. The concentrations of the monoterpene alpha-pinene, shown in Figure 5, are between 0.1 and 0.5 ppb. Other biogenic precursors, not shown in this report, also show similar concentrations in the atmosphere. Based upon these measured values, it is possible that the mass of the nucleation mode products could consist entirely of the oxidation products of measured biogenic precursors. It should also be noted that an estimate of 136 as the mass of aerosol organic phase, is probably low; the lower volatility oxidation products often have higher molecular weights than the parent compound. 


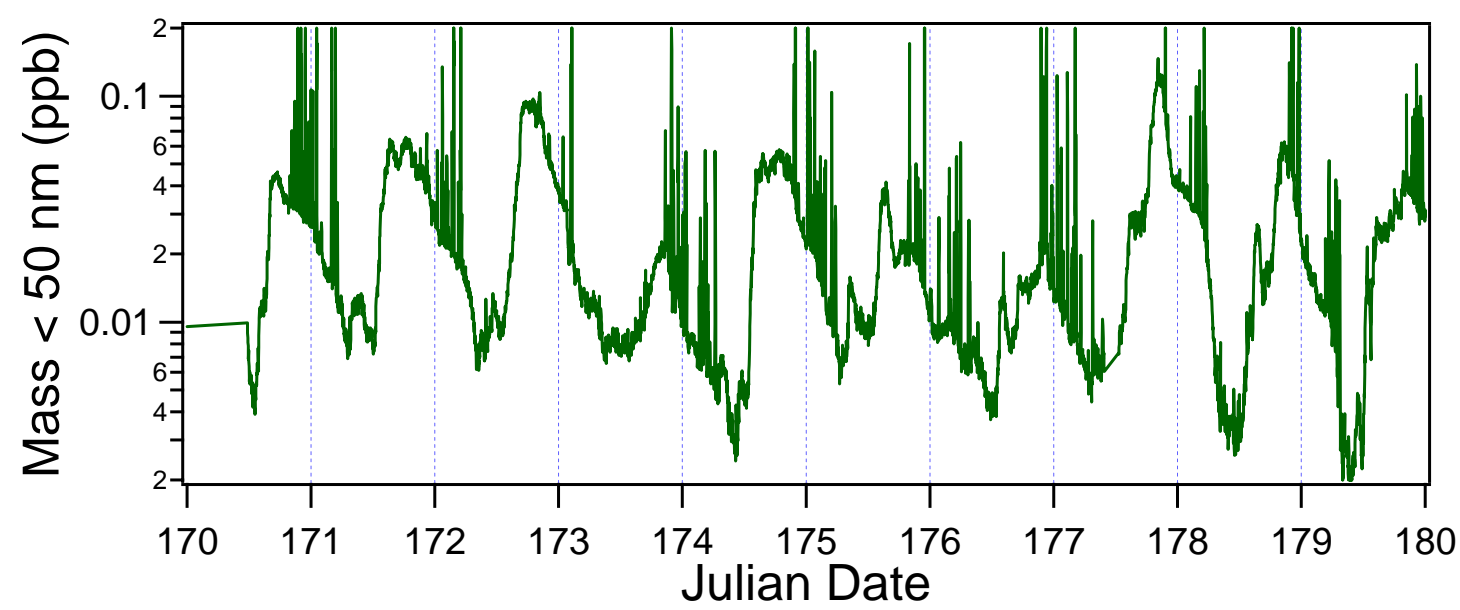

Figure 12: Mass of particles less than $50 \mathrm{~nm}$ calculated from the size distribution shown in Figure 10.

Aerosol impacts due to forest fire emissions:

During the 2002 measurement season, the Blodgett location was affected by a number of regional forest fires. The largest fire signal in the data was due to the Biscuit fire in Southeast Oregon. This fire, started by a lightning strike, lasted from July $13^{\text {th }}$ to November $9^{\text {th }}$, eventually burning approximately 500,000 acres. The Blodgett field site was strongly affected by the fire from approximately August $15^{\text {th }}$ through August 22 . Figure 13 shows plots of total particle scattering, black carbon concentration, and particle size distribution for the period of time affected by the Biscuit Fire. The period of time most affected by the fire can be detected by an increase in the black carbon data, denoted by the area in the red squares in Figure 13. The particle size distributions show the presence of a larger size mode during the period most affected by the fires, as emissions from the fires age and grow in the atmosphere as they are transported to the site. The presence of a larger mode in the size distribution has been observed for fire events from other periods in the years 2002 and 2001. Figure 13 also shows an increase in particle scattering during the same period. Indeed, the particle scattering signal tracks the black carbon signal very well. Scattering is proportional to particle diameter by a power law, therefore the larger particles in the smoke affected periods lead to increased scattering. The correlation between the black carbon and scattering signals implies that the majority of the large particles are largely carbonaceous. This data show how forest fires can dramatically affect visibility, even several hundred miles from the source. 

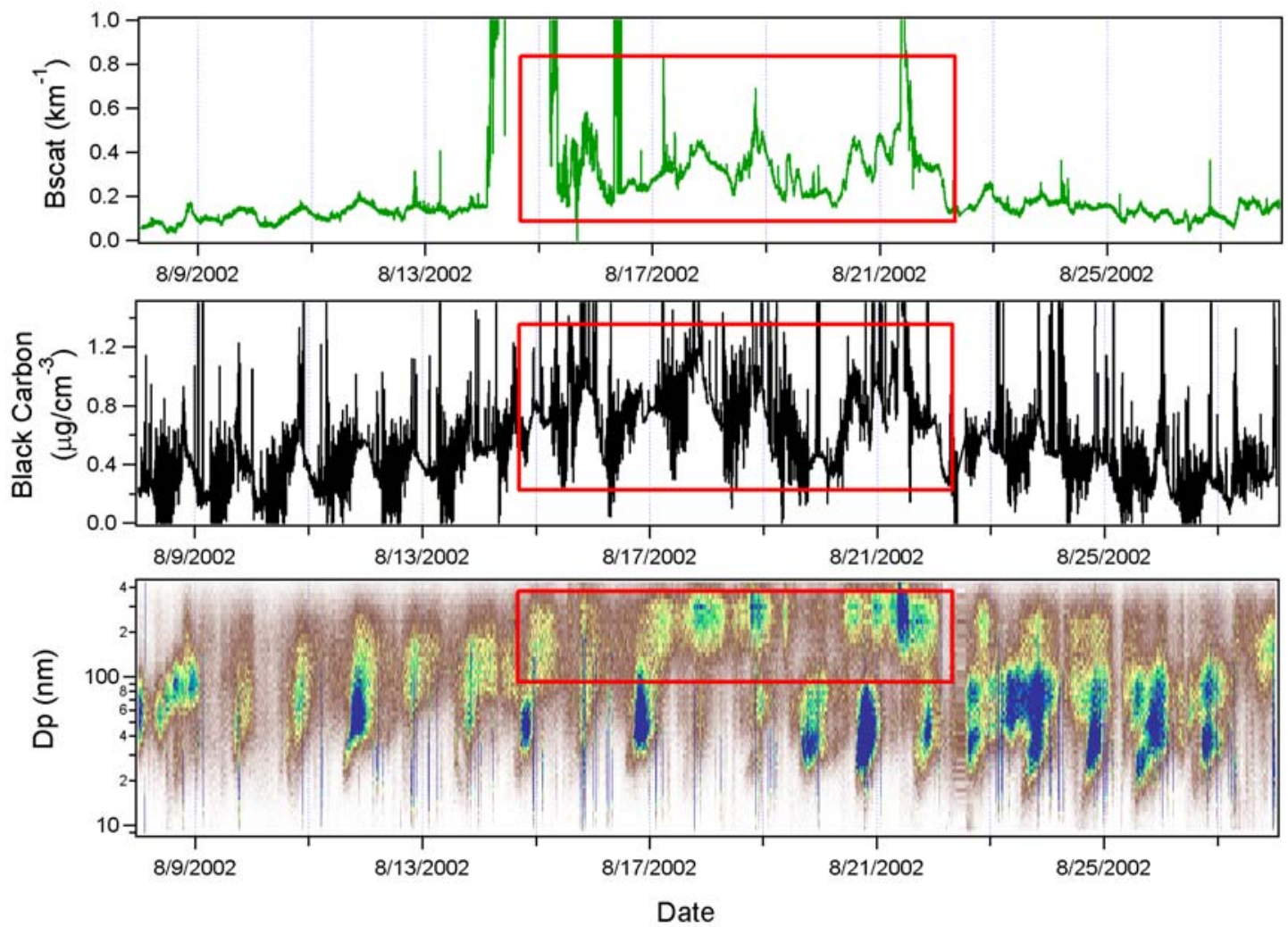

Figure 13: Graph of total particle scattering $\left(\mathrm{km}^{-1}\right)$, black carbon concentration $\left(\mu \mathrm{g} / \mathrm{cm}^{3}\right)$, and particle size distribution for the period of time affected by the Biscuit fire.

Table 5 shows the results from filter measurements performed during the prescribed burns that occurred during late October 2002. The fires were controlled and small in scope, no more than a few acres each. Due to dry conditions, the fires were only set during the evening. The AM filter samples were run from 9:30 AM to 9:30 PM, with the PM sample running from 9:30 PM to 9:30 AM. The data in the table show the total carbon measured on the filter as well as the amount and percentage (in parentheses) that was black carbon. The sample measured on 10/30 during the evening was the only sample of the set where fire emissions were noticeably present at the tower location, which is reflected by the larger concentrations of carbon for that period. The table also includes carbon measurements acquired at different locations: urban (Fresno, CA), remote (also measured in the Sierra Nevada mountains), large fire plume in South Africa. The results show that the carbon levels measured during the controlled burns are similar to those measured in the urban location during the fall, but the percentage of the total carbon that was black carbon was smaller. This result implies that the carbonaceous aerosols emitted from the fire were composed primarily of organic carbon. The total carbon concentrations measured in the Sierra during routine monitoring were not significantly different from many of the controlled burn samples. This is most probably due to the small scope of the burns having a limited effect at the tower site. The results listed for Fresno during the winter show high carbon concentrations, a result largely influenced by the large number of fireplace emissions from homes. The concentrations 
measured in the South African Plume show how large carbon emissions can be directly over a large uncontrolled fire. Both the Fresno and South Africa measurements show that carbon concentrations due to fires can be large, even in urban locations.

Table V: Total and black carbon concentrations in $\mathrm{mg} / \mathrm{m}^{3}$ measured at the Blodgett field location as well as for locations indicative of urban (Fresno), remote (US Remote Sierra), and heavily fire affected (South Africa Plume) locations.

\begin{tabular}{|l|l|l|}
\hline & Total Carbon & Black Carbon \\
\hline \hline 10/30 PM & 7.4 & $0.2(2 \%)$ \\
\hline $10 / 31$ AM & 2.4 & $0.2(7 \%)$ \\
\hline $10 / 31$ PM & 2.2 & $0.13(6 \%)$ \\
\hline 11/1 AM & 2.0 & $0.15(8 \%)$ \\
\hline Fresno Fall & $7 \pm 3$ & $1.4(20 \%)$ \\
\hline Fresno Winter & $34 \pm 11$ & $4.1(12 \%)$ \\
\hline South Africa Plume & 220 & $45(18 \%)$ \\
\hline US Remote Sierra & 2.35 & $0.25(11 \%)$ \\
\hline
\end{tabular}

\section{Acknowledgements}

This research was supported by the Assistant Secretary for Fossil Energy, Office of Natural Gas and Petroleum Technology, through the National Petroleum Technology Office under U.S. Department of Energy Contract No. DE-AC03-765F00098, and the Independent Petroleum Association of Mountain States. The authors are grateful for the efforts of other colleagues who have provided technical assistance; Dennis Debartalomeo, Ken Hom, Kenneth Revzan, Erin McNamara and Toshi Hotchi of LBNL Megan McKay of UC Berkeley, and Sheryl and Dave Rambeau at the Blodgett Forest Research Center.

\section{References}

Anlauf, K.G., MacTavish, D.C., Wiebe, H.A., Schiff, H.I., Mackay, G.I. (1988) Atmos. Environ. 22(8), 1589.

Barthelmie, R.J., and Pryor, S.C. (1999) J. of Geophys. Res. 104(D19), 23657-23669. Bond, TC. (2001) Geophys. Res. Letters, 28, 4075-4078.

Bowman, F.M., Odum, J.R., Seinfeld, J.H., and Pandis, S.N. (1997) Atmospheric Environment 31(23), 3921-3931.

Czoschke, N.M, Jang, M., and Kamens, R.C. (2003) Atmospheric Environment 37(30), 4287-4299.

Cocker, D.R. III, Clegg, S.L., Flagan, R.C., and Seinfeld, J.H. (2001) Atmospheric Environment 35, 6049-6072. 
Collins, D.R., Flagan, R.C., and Seinfeld, J.H. (2002) Aerosol Science and Technology, 36(1), 1-9.

Dillon, M.B, Lamanna, M.S., Schade, G.W., Goldstein, A.H., and Cohen, R.C. (2002) J. of Geophys. Res. 107(D5) 10.1029/2001JD000969.

Dreher, K.L. (2000) Inhalation Toxicol. 12(suppl. 3), 45-57

Dreyfus, G.B., Schade, G.W., and Goldstein, A.H. (2002) J. Geophys. Res. 107(D19) 4365, 10.1029/2001JD001490.

Griffin, R.J., Cocker, D.R., and Seinfeld, J.H. (1999) Environ. Sci. Technol. 33, 24032408.

Griffin, R.J., Dabdub, D., and Seinfeld, J.H. (2002a) J. Geophys. Res. 107(D17), 4332, doi:10.1029/2001JD000541.

Griffin, R.J., Dabdub, D., Kleeman, M.J., Fraser, M.P., Cass, G.R., and Seinfeld, J.H. (2002b) J. Geophys. Res. 107(D17), 4334, doi:10.1029/2001JD000544.

Griffin, R.J., Nguyen, K., Dabdub, D., and Seinfeld, J.H. (2003) Journal of Atmospheric Chemistry 44, 171-190.

Griffin, R.J., Cocker III, D.R., Flagan, R.C., and Seinfeld, J.H. (1999) J. Geophys. Res. 104(D3), 3555-3567.

Grosjean, D, and Seinfeld, J.H. (1987) Atmospheric Environment 23, 1733.

Gundel, L.A., Dod, R.J., Rosen, H., and Novakov, T. (1984) Sci. Tot. Environ. 36, 197. d’Almeida, G.A. (1987) J. Geophys. Res. 92, 3017-3026.

Hansen, ADA; Rosen, H; Novakov, T. (1984) Sci. Tot. Environ. 36, 191-196, 1984.

Hoffmann, T., Odum, J.R., Bowman, F., Collins, D., Klockow, D., Flagan, R.C., and Seinfeld, J.H. (1997) Journal of Atmospheric Chemistry 26, 189-222.

Jang, M., and Kamens, R.M. (1999) Atmospheric Environment 33, 459-474.

Jang, M., and Kamens, R.M. (2001) Environ. Sci. Technol. 35, 4758-4766.

John W. and Reischl G. (1980) J. Air Pollution Control Assoc. 30, 872.

Kalbere, M., Yu, J., Cocker, D.R., Flagan, R.C., and Seinfeld, J.H. (2000) Environ. Sci. Technol. 34, 4894-4901.

Kamens, R.M. and Jaoui, M. (2001) Environ. Sci. Technol. 35, 1394-1405.

Kavouras, I.G., Mihalopoulos, N., Lemonakis, A., and Stehanou, E.G. (1998) Nature 395, 683-686.

Kirchstetter, T.W.; Corrigan, C.E.; Novakov, T. (2001) Atmos. Environ., 35, 1663.

Kirchstetter, TW; Novakov, T. On the wavelength dependence of light absorption by atmospheric aerosol, in preparation for submission to Geophys. Res. Letters, 2004.

Kleindienst, T.E., Smith, D.F., Li. W., Edney, E.O., Driscoll, D.J. et al. (1999) Atmospheric Environment 33,3669-3681. 
Leaitch, W.R., Bottenheim, J.W., Biesenthal, T.A., Li, S.M., Liu, S.K., Asalian, K., Dryfhout-Clark, H., and Hopper, F. (1999) J. Geophys. Res. 104(D7), 8095-8111.

Lamanna, M., and Goldstein, A.G. (1999) J. Geophys. Res. 104(D17), 21247-21262. Mauderly, J (2003) Presentation at the fourth colloquium on PM and Human Health, Pittsburgh, PA, April 1, 2003.

Molenar, J.F., Dietrich, D.L., and Tree, R.M. (1989) In Visibility and Fine Particles, C.V. Mathai, Ed., 374-383. Air and Waste Management Association, Pittsburgh. Novakov, T. (1982) In: Particulate Carbon: Atmospheric Life Cycle, Wolff, G.T., Klimish, R.L. (Eds.). Plenum, New York, pp. 19-41.

Novakov, T. (1981) In: Malissa, H., Grasserbaure, M., Belcher, R. (Eds.), Nature, Aim and Methods of Microchemistry. Springer-Verlag, New York, pp. 141-165.

O’Dowd, C.D., Aalto, P., Hämeri, K, Kulmala, M., Hoffmann, T. 2002 Nature 416, 497.

Odum, J.R., Hoffmann, T., Bowman, F., Collins, D., Flagan, R.C., and Seinfeld, J.H. (1996) Environ. Sci. Technol. 30(6), 2580-2585.

Odum, J.R, Jungkamp, T.P.W., Griffen, R.J., Forster, H.J.L., Flagan, R.C., and Seinfeld, J.H. (1997) Science 276, 96-99.

Pandis, S.N., Paulsen, S.E., Seinfeld, J.H., and Flagan, R.C. (1991) Atmospheric Environment 25, 997.

Pandis, S.N., Harley, R.A., Cass, G.R., and Seinfeld, J.H. (1992) Atmospheric Environment 26A, 2269-2282.

Pandis, S.N., Wexler, A.S., and Seinfeld, J.H. (1993) Atmospheric Environment 27, 2403.

Pankow, J.F. (1994) Atmospheric Environment 28(2), 185-188.

Pankow, J.F. (1994) Atmospheric Environment 28(2), 189-193.

Pankow, J.F., Seinfeld, J.H, Asher, W.E., and Erdakos, G.B. (2001) Environ. Sci. Technol. 35, 1164-1172.

Pun, B.K., Griffin, R.J., Seigneur, C., and Seinfeld, J.H. (2002) J. Geophys. Res. 107(D17), 4333, doi:10.1029/2001JD000542.

Rogge, W.F., Mazurek, M.A., Hildemann, L.M., and Cass, G.R. (1993) Atmospheric Environment 27, 1309-1330.

Schauer, J.J., Kleeman, M.J., Cass, G.R., and Simoneit, B.R.T. (1999a) Environ. Sci. Technol. 33, 1566-1577.

Schauer, J.J., Kleeman, M.J., Cass, G.R., and Simoneit, B.R.T. (1999b) Environ. Sci. Technol. 33, 1578-1587. 
Schauer, J.J., Kleeman, M.J., Cass, G.R., and Simoneit, B.R.T. (2001) Environ. Sci. Technol. 35, 1716-1728.

Seinfeld, J. and Pandis, S. (1998) Atmospheric Chemistry and Physics John Wiley \& Sons, New York.

Seinfeld, J.H., Erdakos, G.B., Asher, W.E., and J.F. Pankow (2001) Environ. Sci. Technol. 35, 1806-1817.

Turpin, B.J.; Huntzicker, J.J.; and Hering, S.V. (1994) Atmos. Environ., 28, 3061. U.S. EPA (2003) Air Quality Criteria for Particulate Matter (Fourth External Review Draft). U.S. Environmental Protection Agency, Office of Research and Development, National Center For Environmental Assessment, Research Triangle Park Office, Research Triangle Park, NC, EPA/600/P-99/002aD and bD.

Yu, J., Cocker, D.R., Griffin, R.J., Flagan, R.C., and Seinfeld, J.H. (1999a) Journal of Atmospheric Chemistry 34, 207-258.

Yu, J., Griffin, R.J., Cocker, D.R. III, Flagan, R.C., Seinfeld, J.H., and Blanchard, P. (1999b) Geophys. Res. Lett. 26, 1145-1148.

Yu, J., Flagan, R.C., and Seinfeld, J.H. (1999c) Environ. Sci. Technol. 32, 2357-2370. Wang, S.C., and Flagan, R.C. (1990) Aerosol Sci. and Technol. 13, 230. 